\title{
Review Article \\ Prevention of Contrast-Induced Nephropathy through a Knowledge of Its Pathogenesis and Risk Factors
}

\author{
Michele Andreucci, ${ }^{1}$ Teresa Faga, ${ }^{1}$ Antonio Pisani, ${ }^{2}$ Massimo Sabbatini, ${ }^{2}$ \\ Domenico Russo, ${ }^{2}$ and Ashour Michael ${ }^{1}$ \\ ${ }^{1}$ Nephrology Unit, Department of Health Sciences, Magna Graecia University, Salvatore Venuta Campus, Viale Europa, \\ Loc. Germaneto, 88100 Catanzaro, Italy \\ ${ }^{2}$ Nephrology Unit, Department of Public Health, University of Naples Federico II, Via Pansini No. 5, 80131 Naples, Italy
}

Correspondence should be addressed to Michele Andreucci; andreucci@unicz.it

Received 19 July 2014; Accepted 30 September 2014; Published 30 November 2014

Academic Editor: Anja Verhulst

Copyright ( 2014 Michele Andreucci et al. This is an open access article distributed under the Creative Commons Attribution License, which permits unrestricted use, distribution, and reproduction in any medium, provided the original work is properly cited.

\begin{abstract}
Contrast-induced nephropathy (CIN) is an iatrogenic acute renal failure (ARF) occurring after the intravascular injection of iodinated radiographic contrast media. During the past several years, in many patients undergoing computed tomography, iodinated contrast media have not been used for the fear of ARF, thereby compromising the diagnostic procedure. But recent studies have demonstrated that $\mathrm{CIN}$ is rarely occurring in patients with normal renal function and that preexisting chronic renal failure and/or diabetes mellitus represent(s) predisposing condition(s) for its occurrence. After the description of CIN and its epidemiology and pathophysiology, underlying the important role played by dehydration and salt depletion, precautions for prevention of CIN are listed, suggested, and discussed. Maximum priority has to be given to adequate hydration and volume expansion prior to radiographic procedures. Other important precautions include the need for monitoring renal function before, during, and after contrast media injection, discontinuation of potentially nephrotoxic drugs, use of either iodixanol or iopamidol at the lowest dosage possible, and administration of antioxidants. A long list of references is provided that will enable readers a deep evaluation of the topic.
\end{abstract}

\section{Introduction}

Contrast-induced nephropathy (CIN), which is also called contrast-induced acute kidney injury (CI-AKI), is an iatrogenic disease occurring after the intravascular injection of iodinated radiographic contrast media. CIN was first described in a patient with multiple myeloma receiving intravenous pyelography [1]. Today, the common opinion is that multiple myeloma per se cannot be considered a main risk factor for developing acute kidney injury following intravascular administration of iodinated contrast media [2]. In 2004 Gleeson and Bulugahapitiya [3] indicated CIN as the third leading cause of hospital-acquired acute renal failure (ARF) after surgery and hypotension, being responsible for $12 \%$ of all cases of ARF in hospital.

Meinel et al. [4] have recently underlined (a) that after modern iodinated radiographic media had been introduced in clinical practice they have been considered responsible for ARF [5], (b) that numerous subsequent noncontrolled observational studies appeared to confirm the causal role of contrast media for most cases of ARF following their intravascular administration [6], and (c) that, consequently, for many patients undergoing computed tomography (CT) iodinated contrast media have not been used for the fear of ARF, thereby compromising the diagnostic procedure [7]. Katzberg and Newhouse [8] have challenged this concept particularly for intravenous (i.v.) injection of iodinated contrast media.

Thus, the logical question that the clinicians ask themselves is whether CIN is still a clinical problem.

\section{Contrast-Induced Nephropathy}

CIN may be defined as an ARF that occurs within 24-72 hrs of exposure to i.v. or intra-arterial iodinated contrast media 
that cannot be attributed to other causes. In most cases it is a nonoliguric ARF with an asymptomatic transient decline in renal function, so that it may go undetected by those clinicians who do not check the renal function in the days following the contrast administration, as it is the case in nonhospitalized patients. The renal function impairment is mirrored by an absolute increase by $0.5 \mathrm{mg} / \mathrm{dL}$ (or greater) or relative increase by $25 \%$ (or greater) of serum creatinine from baseline or, better, by a decrease to $30-60 \mathrm{~mL} / \mathrm{min}$ (renal insufficiency) or less in the estimated glomerular filtration rate (eGFR), that is, the creatinine clearance calculated using the MDRD (modification of diet in renal disease) formula [9] or the CKD-EPI (chronic kidney disease epidemiology collaboration) equation [10], or the very simple Cockcroft-Gault formula [11]. The rise in serum creatinine is peaking on the third to fifth day, returning to baseline within 10-14 days [12].

In some cases, CIN may cause a more severe impairment of renal function with oliguria $(<400 \mathrm{~mL} / 24 \mathrm{hrs})$, requiring dialysis. In these cases the mortality is high.

The clinical feature and the management of CIN are the same as that for ARF due to other causes [13-15].

\section{Incidence of CIN}

The early literature had greatly overestimated the incidence of CIN [16]. CIN occurs in up to $5 \%$ of hospitalized patients who exhibit normal renal function prior to the injection of contrast medium [17] and in about $2 \%$ [18] or even $1 \%$ of outpatients with eGFR $>45 \mathrm{~mL} / \mathrm{min}$ per $1.73 \mathrm{~m}^{2}$ [19].

Thus, CIN is uncommon in patients with normal preexisting renal function. Actually, it occurs more frequently in patients with renal impairment, particularly if associated with diabetic nephropathy [8]. Among all procedures utilizing contrast agents for either diagnostic or therapeutic purposes, coronary angiography and percutaneous coronary interventions are associated with the highest rates of CIN [20]. This is mainly related to (a) the intra-arterial injection, (b) the high dosage of the contrast used, and (c) the type of patients who are usually in advanced age, with one or more comorbid conditions, such as advanced vascular disease, severe longstanding hypertension, diabetes, and some renal function impairments [18].

In a retrospective study analyzing 11,588 patients undergoing CT either without contrast or with the low-osmolar contrast medium iohexol or the isoosmolar contrast medium iodixanol Bruce et al. [21] observed that the incidence of CIN in the low-osmolar contrast medium group was similar to that of the control group up to a serum creatinine level of $1.8 \mathrm{mg} / \mathrm{dL}$; but serum creatinine above $1.8 \mathrm{mg} / \mathrm{dL}$ was associated with a higher incidence of CIN in the low-osmolar contrast medium group; there was no significant difference in the incidence of CIN between the isoosmolar contrast medium and the control groups for all baseline serum creatinine values.

Recently, McDonald et al. [22] carried out a retrospective study on 53,439 patients in whom serum creatinine was regularly checked. They evaluated the effects of i.v. iodinated contrast media exposure to the incidence of CIN: the incidence was not significantly different in contrast media group compared to control group. In a meta-analysis of controlled studies by the same group [23] in patients exposed to i.v. contrast media compared with patients undergoing an imaging examination without contrast media (control group), the incidence of CIN, dialysis, and death was similar in the contrast media group and in the control group. They concluded that i.v. iodinated contrast media may not be the causative agent in diminished renal function after contrast material administration.

In an unselected, prospective, consecutive population of outpatients who received the low-osmolar, nonionic contrast iopamidol-370 for a contrast-enhanced CT study in the emergency department of a large, academic, tertiary care center Mitchell et al. [24] found an incidence of CIN of $11 \%$ (70 out of 633) of the patients enrolled; six of the 70 cases subsequently developed severe renal failure, five of whom required dialysis or died.

In a retrospective study performed over a 10 -year period in 20,242 adult inpatients (10,121 untreated and 10,121 treated with i.v. iodinated contrast media) Davenport et al. [25] found that i.v. low-osmolality iodinated contrast media is a risk factor for nephrotoxicity in patients with a stable eGFR < $30 \mathrm{~mL} / \mathrm{min} / 1.73 \mathrm{~m}^{2}$. No nephrotoxicity was observed in patients with a pretomography eGFR $>45 \mathrm{~mL} / \mathrm{min} / 1.73 \mathrm{~m}^{2}$. The authors concluded that i.v. contrast medium is a nephrotoxic risk factor but not in patients with a stable serum creatinine $<1.5 \mathrm{mg} / \mathrm{dL}$ or eGFR $>45 \mathrm{~mL} / \mathrm{min} / 1.73 \mathrm{~m}^{2}[26]$.

Rudnick and Feldman [27] have evaluated whether CIN is causally related to mortality and to what extent could mortality in patients undergoing contrast procedures be reduced by preventing CIN. After reviewing observational studies and clinical trials, they concluded that the deaths of some patients with CIN are complicated by factors that cannot be directly related to the use of contrast media, such as liver disease, sepsis, respiratory failure, and bleeding. On the other hand, patients undergoing coronary diagnostic procedures may already have some renal problems [28] even without using contrast media. It is, however, plausible that CIN contributes to cardiovascular causes of death in patients with CIN [27].

Concerning the long term outcome of patients who have had CIN, Solomon et al. [29] have studied in 294 patients, with follow-up of at least 1 year after contrast exposure, the relationship of CIN to long-term adverse events, such as death, stroke, myocardial infarction, end-stage kidney disease, percutaneous coronary revascularization, coronary artery bypass graft surgery, cardiac arrest, development of congestive heart failure or pulmonary edema, and the need for permanent pacing. The rate of these long-term adverse events was higher in individuals who had had CIN.

Permanent severe renal failure requiring dialysis occurs in $10 \%$ of patients with preexisting renal failure who develop further reduction in renal function after coronary angiography [30].

\section{Pathophysiology of CIN}

The intravascular injection of iodinated radiographic contrast media is followed by an immediate haemodynamic renal 


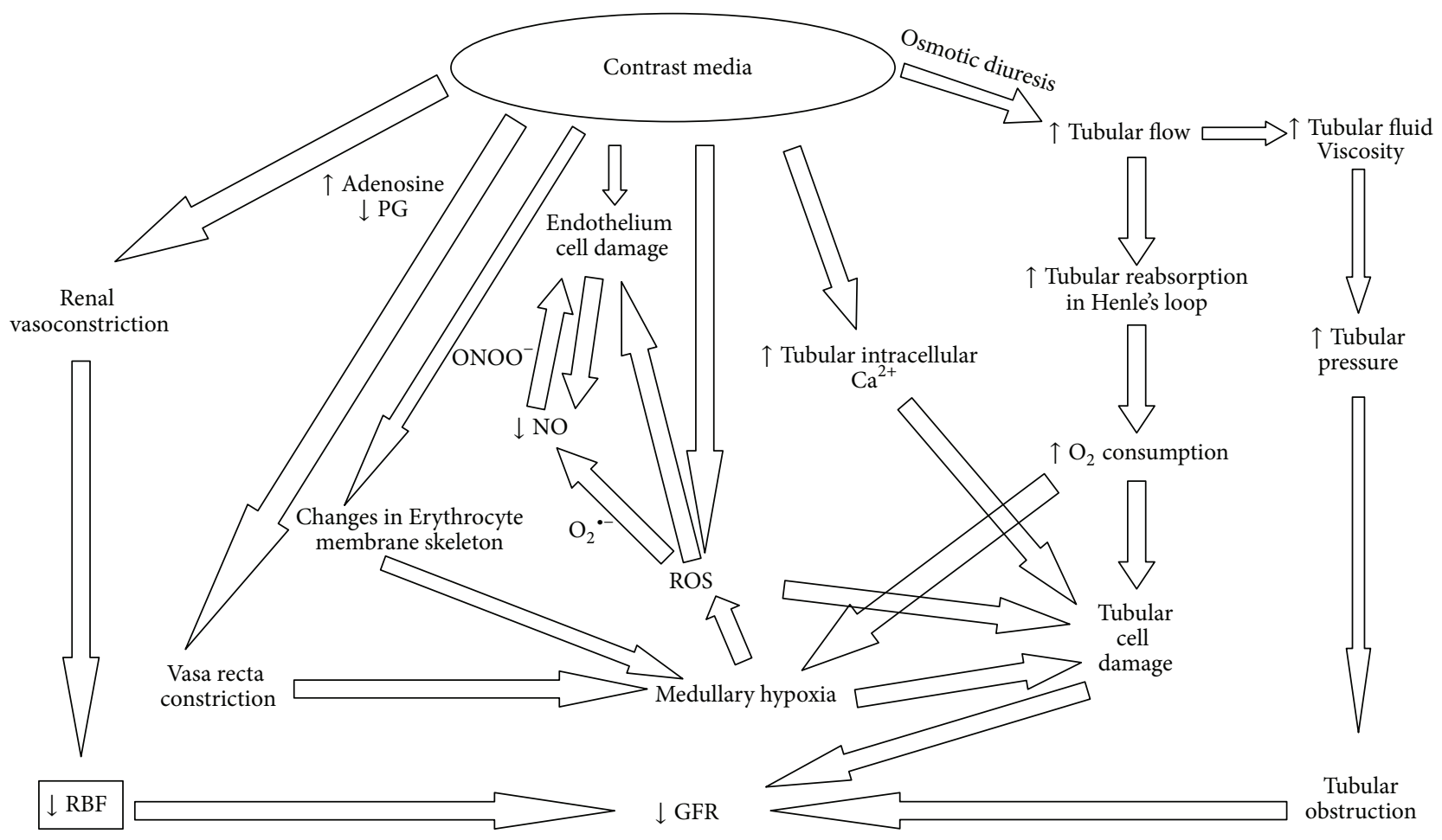

FIGURE 1: The complex mechanisms by which iodinated radiographic contrast media cause the fall of GFR.

biphasic response: firstly a rapid and short renal vasodilatation with an increase in renal blood flow (RBF) followed by a prolonged vasoconstriction with an increase in intrarenal vascular resistances and a reduction in total RBF. The extrarenal vessels undergo a transient vasoconstriction followed by a stable decrease in vascular peripheral resistances [31].

These haemodynamic changes cause a decrease of glomerular filtration rate (GFR) and a renal ischaemia particularly in the renal medulla. The outer medulla, even under normal physiological conditions, receives little oxygen $\left(\mathrm{O}_{2}\right)$ (because of its distance from the descending vasa recta) despite its high local oxygen consumption due to the important active tubular reabsorption in S3 segments of proximal renal tubules and in the medullary thick ascending limb of the Henle's loops that are located here. Prostaglandins, nitric oxide (NO), and adenosine continuously adjust medullary tubular transport activity to the limited available $\mathrm{O}_{2}$ supply, by enhancing the regional blood flow and downregulating the tubular transport [32]. Defects in one or more of these protective mechanisms will cause medullary hypoxia. The haemodynamic changes induced by contrast media will make medullary hypoxia quite severe (Figure 1).

However, radiographic contrast media also induce an osmotic diuresis that increases fluid delivery and consequent tubular reabsorption in the ascending limb of Henle's loops, thereby increasing energy need and $\mathrm{O}_{2}$ consumption: the result will be a worsening of medullary hypoxia [33-35] (Figure 1).

Medullary hypoxia causes the formation of reactive oxygen species (ROS) [36-38] that may exert direct tubular and vascular endothelial injury and might further intensify renal parenchymal hypoxia by virtue of endothelial dysfunction $[39,40]$ (Figure 1).

ROS cause a decrease in NO [36, 41]. The reaction between the ROS superoxide anion and nitric oxide leads to the formation of the more powerful oxidant peroxynitrite [42] which may cause more damage to the endothelial cells.

The injection of iodinated contrast media increases ROS production and renal oxidative stress which, in turn, mediates the damage to cell membranes leading to cellular apoptosis and necrosis, particularly in medullary thick ascending limbs and in S3 segments of proximal renal tubules of the outer medulla [36].

Recently, Pisani et al. [43] have demonstrated that a recombinant manganese superoxide dismutase administered in vivo to rats undergoing diatrizoate treatment was able to reduce renal oxidative stress, thereby preventing the reduction of GFR and the renal histological damage that follows contrast media administration.

Furthermore, iodinated contrast media also possess a direct cytotoxic property on endothelial and renal tubular cells, leading to apoptosis and necrosis [44]. The intravascular injection of contrast agents causes a direct endothelial damage that has been seen by scanning electron microscopy: cell shrinkage, nuclear protrusion, fenestration of the endothelial layer and formation of microvilli ("blebbing") on the cell membrane, and cellular apoptosis [45]. The damaged endothelial cells contribute to the decrease in NO in the vasa recta [41] (Figure 1).

After the intravascular injection the iodinated contrast media are filtered by the glomeruli and are concentrated 
within the renal tubules (because of tubular fluid reabsorption), thereby exposing the renal tubular cells to a direct damage, which have been observed in studies of isolated tubular segments and cultured cells substantiated by disruption of cell integrity and apoptosis $[46,47]$.

The biochemical changes in the damaged epithelial tubular cells have been studied by evaluating the changes in major intracellular signalling pathways involved in cell survival, death, and inflammation [38, 48-52] in vitro in cultured renal tubular cells [53]. These aspects have been clarified in primary human tubular cells as well as in HK-2 cells exposed to different contrast media. A decrease of cell viability, secondary to a reduced activation/phosphorylation of Akt and of ERK 1/2, have been demonstrated, which was alleviated by transfecting the HK-2 cells with a constitutively active form of Akt [54]. In HK-2 cells, oxidative stress causes an increase in phosphorylation of Akt $[50,53]$ contrary to the effect of contrast media. In $\mathrm{HK}-2$ cells contrast media affect the activation/deactivation of transcription factors, like FoxO3a and STAT3, that control the genes involved in apoptosis and cell proliferation [54-56]. In vivo animal studies as well as in vitro studies suggest that iodinated contrast media can directly induce caspase-mediated apoptosis of renal tubular cells [57]. Contrast-induced apoptosis may also be due to the activation of shock proteins and the concurrent inhibition of cytoprotective enzymes and prostaglandins $[58,59]$.

In physiological conditions, the $\mathrm{Na}^{+} / \mathrm{Ca}^{2+}$ exchanger (NCX) is pumping the $\mathrm{Ca}^{2+}$ outside the renal tubular epithelial cells by using the $\mathrm{Na}^{+}$concentration gradient across the cell membrane; this process is keeping low the intracellular $\mathrm{Ca}^{2+}$. Under pathological conditions, such as in CIN, NCX can reversibly extrude $\mathrm{Na}^{+}$for $\mathrm{Ca}^{2+}$ influx thereby leading to intracellular $\mathrm{Ca}^{2+}$ overload. Intracellular $\mathrm{Ca}^{2+}$ overload is considered to be a key factor in ischemic cell injury and in CIN [60-62].

We have mentioned that the concentration of the contrast medium increases considerably within the tubular lumen because of tubular fluid reabsorption. Thus, the tubular fluid osmolality increases. Because of the exponential concentration-viscosity relationship, an overproportional increase in tubular fluid viscosity occurs [63]. Since the fluid flow rate through a tube increases with the pressure gradient and decreases with the flow resistance and since the resistance increases proportionally to fluid viscosity, the increased viscosity caused by a contrast medium increases the intratubular pressure [63]. Thus, the osmotic diuresis caused by the contrast media raises the intratubular pressure with a condition of tubular obstruction that contributes to the tubular epithelial damage and to the fall of GFR [35] (Figure 1).

The effect on morphology of erythrocytes by contrast media has also been studied $[64,65]$, with formation of echinocytes and stomatocytes observed upon incubation of erythrocytes with contrast media which may have a negative effect on the rheology of the blood [41]. More recent work has shown that contrast media affect the membrane skeleton of erythrocytes, with iopromide causing drastic changes in the band3-spectrin network compared with iodixanol that may contribute to microcirculatory disorders (especially in patients with coronary artery disease) and gas transport, contributing to tissue hypo-oxygenation [66].

\section{The Iodinated Radiographic Contrast Media}

The iodinated radiographic contrast media have different osmolalities and viscosities. The ionic High-Osmolar Contrast Media (HOCM, e.g. diatrizoate) have an osmolality of 1500 to $1800 \mathrm{mOsm} / \mathrm{kg}$, that is, 5-8 times the osmolality of plasma. Nonionic Low-Osmolar Contrast Media (LOCM e.g., iohexol) have an osmolality of 600 to $850 \mathrm{mOsm} / \mathrm{kg}$, that is, 2-3 times the osmolality of plasma. Nonionic isoosmolar contrast media (IOCM, e.g., iodixanol) have an osmolality of approximately $290 \mathrm{mOsm} / \mathrm{kg}$, that is, the same osmolality as plasma $[12,35,67]$.

Heinrich et al. [47] compared the cytotoxic effects of dimeric and monomeric iodinated contrast media on renal tubular cells in vitro. Results of this study indicated that HOCM have a greater potential for cytotoxic effects on proximal tubular cells in vitro than do LOCM or IOCM. At equal iodine concentrations $(300 \mathrm{mg} \mathrm{I} / \mathrm{mL})$, the HOCM ioxithalamate showed stronger cytotoxic effects than did other contrast media. It has been demonstrated that the use of LOCM rather than HOCM is beneficial in reducing the incidence of CIN in patients with preexisting renal failure [68-71]. Adverse reactions to contrast media with the occurrence of CIN range from $5 \%$ to $12 \%$ for HOCM and from $1 \%$ to $3 \%$ for LOCM. Thus, the HOCM are used less frequently. There is no difference in the cytotoxicity of LOCM iomeprol and IOCM iodixanol at equal iodine concentrations in renal proximal tubular cells in vitro [72]. Recent studies and meta-analyses have shown no significant difference in the rates of CIN between IOCM and LOCM [72-75]; only the LOCM iohexol seems to be more nephrotoxic $[68,76]$. The IOCM iodixanol seems less nephrotoxic than the LOCM iohexol, at least in patients with intra-arterial administration of the drug and renal insufficiency $[72,77]$.

Iodinated radiographic contrast media have also a different viscosity. The low osmolality achieved with the IOCM has come at the price of considerably increased viscosity; at comparable iodine concentrations and X-ray attenuation, the nonionic dimeric IOCM have about twice the viscosity of nonionic monomeric LOCM $[63,78,79]$.

\section{Preexisting Impairment of Renal Function and Diabetes Mellitus}

CIN occurs more frequently in subjects with renal insufficiency, irrespective of cause. An eGFR of $60 \mathrm{~mL} / \mathrm{min} / 1.73 \mathrm{~m}^{2}$ is a reliable cut-off point for identifying patients at high risk for the development of CIN [12]. The higher the baseline creatinine value is or, better, the lower the eGFR is, the greater the risk of CIN is. Patients with chronic renal failure (CRF) have defective antioxidant systems [80] and increased oxidative stress associated with inflammation and endothelial dysfunction [81]. This may explain why preexisting renal failure represents the most common condition predisposing to the development of CIN [35]. 
Since clinical need for diagnostic and therapeutic procedures using contrast media (such as coronary angiography and percutaneous coronary interventions) is increased particularly in patients with cardiovascular diseases whose renal function is frequently impaired, the occurrence of renal damage by contrast media is quite frequent.

Diabetes mellitus is another predisposing factor to CIN, particularly when associated with impairment of renal function $[82,83]$. At any given degree of baseline GFR, diabetes doubles the risk of developing CIN compared with nondiabetic patients. The incidence of CIN in diabetic patients varies from 5.7 to $29.4 \%$ [20]. Many authors do not regard the presence of diabetes mellitus in the absence of renal failure as a risk factor for CIN. In diabetic patients with preserved renal function and without other risk factors, in fact, the incidence of CIN has appeared comparable to that of a nondiabetic population [84]. Coupling chronic kidney disease and diabetes dramatically increases the risk for CIN compared with that observed for chronic kidney disease alone [85].

Furthermore, the effects of diabetes and prediabetes on the development of CIN have been investigated by Toprak et al. [86] on 421 patients with chronic kidney disease undergoing coronary angiography; 137 had diabetes mellitus, 140 had prediabetes and 144 had a normal fasting glucose; CIN occurred in $20 \%(\mathrm{RR}=3.6), 11 \%(\mathrm{RR}=2.1)$, and $5.5 \%$, respectively. Haemodialysis was required in $3.6 \%$ and $0.7 \%$ of those with diabetes and prediabetes, respectively. A serum glucose concentration above $124 \mathrm{mg} / \mathrm{dL}(6.8 \mathrm{mmol} / \mathrm{l})$ was the best cut-off point for prediction of CIN.

The biologically active endothelins, produced by proteolysis of the precursor prepro-endothelins under the action of endothelin-converting enzyme, are increased in circulating blood of diabetics. In diabetic patients there is also a hypersensitivity of renal vessels to adenosine $[87,88]$. These factors may justify the predisposition of diabetics to the development of CIN [34].

\section{Additional Predisposing Factors}

The European Society of Urogenital Radiology has stated that the real risks for CIN are represented by preexisting renal impairment particularly when secondary to diabetic nephropathy, but also to salt depletion and dehydration, congestive heart failure, an age greater than 70 years, and concurrent use of nephrotoxic drugs $[89,90]$.

Salt depletion and dehydration deserve a special discussion. Dehydration is the decrease of body water. This, for instance, is what occurs in old patients who do not force themselves to drink water during the day, due to impaired sensation of thirst [91]. But the term dehydration is frequently used to indicate salt and water depletion with contraction of extracellular volume. Anyhow, dehydration and salt depletion are responsible for the reduction of "effective" intravascular volume [92]. The "effective" circulating blood volume may be defined as the relative fullness of the arterial tree as determined by cardiac output, peripheral vascular resistance, and total blood volume [14]. A reduction of the "effective" circulating blood volume may be due to congestive heart failure, compromised left ventricle systolic performance, prolonged hypotension or liver cirrhosis or nephrotic syndrome or salt depletion [92].

When we perform intravascular injection of contrast media in patients who are dehydrated and/or hypovolemic, water and salt overreabsorption occurs in renal tubules causing a further increase of the intratubular concentration of contrast material and, due to the concentration-viscosity relationship, overproportionally increasing tubular fluid viscosity. This is why dehydration and/or volume contraction (salt depletion following abnormal gastrointestinal, renal or dermal fluid losses associated with insufficient salt intake and reduction of "effective" circulating blood volume [93]) are major risk factors for CIN. Thus, prehydration and correction of volume depletion are very important in all patients before any diagnostic and therapeutic procedures requiring intravascular injection of contrast media [94].

Advanced age [20,95], anemia [96], severe congestive heart failure, or compromised left ventricle systolic performance [20], sepsis [3, 95, 97], and renal transplant [98] represent additional risk factors for CIN.

In an interesting study of Ranucci et al. [99] the risk of postoperative acute renal insufficiency after cardiac surgery in 423 adults was increased by the volume of administered radiocontrast medium and was more likely when there was a short interval between angiography and subsequent cardiac surgery. The authors suggested that cardiac surgery should be delayed beyond 24 hours of exposure to contrast agents when feasible and that the use of these agents should be minimized.

The concomitant use of nephrotoxic drugs, such as aminoglycosides, cyclosporine $\mathrm{A}$, amphotericin, cisplatin, dipyridamole, and nonsteroidal anti-inflammatory drugs, is undoubtedly another factor favoring CIN. The authors of many studies believe that patients with CRF under treatment with angiotensin-converting enzyme inhibitors (ACEIs) or angiotensin II receptor blockers (ARBs) are at high risk for developing CIN [100-106], particularly in the elderly [107]. According to KDIGO (kidney disease improving global outcomes) guidelines for Acute Kidney Injury Work Group, there is insufficient evidence to recommend discontinuation of these medications prior to contrast administration [108].

\section{Precautions for Prevention of CIN}

Thus, CIN is not as frequent as it was believed to be in the past few years. However, it does occur in high risk patients. This makes it necessary to use all precautions that may prevent contrast media-nephrotoxicity [12, 109-112].

The first precaution is that, in patients undergoing a radiographic procedure, the renal function should be monitored by measuring serum creatinine before and once daily for 5 days after the contrast medium injection [3].

The second precaution is that potentially nephrotoxic drugs (aminoglycosides, vancomycin, amphotericin B, dipyridamole, metformin, and nonsteroidal anti-inflammatory drugs) should be discontinued before the radiographic procedure [12]. If aminoglycosides are necessary, it is suggested to follow the European Renal Best Practice [113] recommendation: "Do not use more than one shot of aminoglycosides for the treatment of infections... In patients with normal kidney 
function in steady state, aminoglycosides are administered as a single-dose daily rather than multiple-dose... monitoring aminoglycoside drug levels."

Special attention should be paid to the use of metformin, an oral antihyperglycemic drug used to treat type II diabetes that stimulates intestinal production of lactic acid. Metformin is excreted unchanged almost entirely by the kidneys; thus, it is retained in cases of CIN and may cause a severe lactic acidosis that can be fatal. Thus, this medication should be discontinued 12 hours before the administration of contrast agent and not be resumed until at least 36 hours after the procedure, or even longer if the serum creatinine has not returned to baseline [114].

The third precaution is an adequate hydration of the patient $[115,116]$. Not only should the old suggestion to limit fluid intake starting the day before contrast administration be abolished, but it is important to give an adequate supplement of water. It has been suggested to give the patient $500 \mathrm{~mL}$ of water orally before and 2,500 $\mathrm{mL}$ for 24 hours after contrast injection to secure urine output of at least $1 \mathrm{~mL} / \mathrm{min}$ in a nondehydrated patient [117]. In high-risk patients it may be useful to implement, instead, the i.v. infusion of $0.9 \%$ saline at a rate of about $1 \mathrm{~mL} / \mathrm{kg}$ b.w. per hour, beginning 6-12 hours before the procedure and continuing for up to 12-24 hours after the radiographic examination, provided that urine output is appropriate and the cardiovascular condition allows it [3, 115]. The increase of urine output that follows the hydration will limit the duration of contrast material contact with the epithelial cells of the renal tubules and consequently its cytotoxicity $[118,119]$. Some investigators have obtained better results using sodium bicarbonate instead of sodium chloride [120-129]: 154-mEq/L infusion of sodium bicarbonate as a bolus of $3 \mathrm{~mL} / \mathrm{kg}$ b.w./hour for 1 hour before the administration of contrast, followed by $1 \mathrm{~mL} / \mathrm{kg} /$ hour for 6 hours during and after the procedure [121]. The increase of bicarbonate excretion would decrease the urine acidification, thereby reducing the production and increasing the neutralization of oxygen free radicals $[123,124,130-132]$. Other investigators did not find any benefit with sodium bicarbonate versus sodium chloride [133-136]. The European Renal Best Practice [113] "recommends volume expansion with either isotonic sodium chloride or sodium bicarbonate solutions, rather than no volume expansion, in patients at increased risk for CIN."

The fourth precaution is choosing the least nephrotoxic iodinated agent. As mentioned above, iodixanol (IOCM) and iopamidol (LOCM) appear to be contrast agents of choice to reduce risk of CIN [73].

The fifth precaution is the use of contrast media at the lowest dosage possible. The use of large doses and multiple injections within $72 \mathrm{hrs}[3,95,137]$, in fact, represent risks for CIN that are dose-dependent [138-142]. High doses of contrast agents are required in coronary angiography and percutaneous coronary interventions. Fortunately, the development of newer imaging technologies has facilitated faster image acquisition; this has enabled radiologists to perform studies with less intravascular contrast, because the duration of time over which contrast needs to be administered has shortened [12, 143]. Anyhow for these procedures some formulas have been suggested to calculate the dosage that is least dangerous for renal function: (a) Cigarroa's formula: $5 \mathrm{~mL}$ of contrast per $\mathrm{kg}$ b.w./serum creatinine $(\mathrm{mg} / \mathrm{dL})$ with maximum dose acceptable of $300 \mathrm{~mL}$ for diagnostic coronary arteriography [144]; (b) Laskey's formula: volume of contrast to eGFR ratio with a cut-off point of the ratio at 3.7 for percutaneous coronary intervention [145]; recently the cutoff point has been placed at 2.0: below a ratio of 2.0 CIN may be a rare complication of percutaneous coronary intervention, which would increase dramatically at a ratio of $3.0[143,146]$; (c) a ratio of the grams of iodine to eGFR; a ratio of 1.42, or even better a ratio of 1.0, would prevent CIN [143].

\section{Use of Antioxidants for Preventing CIN}

We have seen that ROS play an important role in the nephrotoxicity by iodinated radiocontrast agents. Thus, it has been thought that antioxidants could be useful in preventing CIN. $\mathrm{N}$-acetylcysteine has been the first tested antioxidant, considering also its double properties, as a free-radical scavenger as well as a drug able to increase the vasodilating effect of NO [3, 39, 147]. Lee et al. [148] treated human embryonic kidney cells with three different contrast media: the ionic HOCM ioxithalamate, the nonionic LOCM iopromide, and the IOCM iodixanol; all three contrast media caused a significant reduction of cell viability at 24 hours $(P<0.001)$; shortduration pretreatment with $\mathrm{N}$-acetylcysteine significantly improved cell viability compared with no $\mathrm{N}$-acetylcysteine pretreatment $(P<0.001)$. Despite controversial results observed in high risk patients [13, 149-158], it has been suggested to use $\mathrm{N}$-acetylcysteine in high-risk patients either with an oral dose of $600 \mathrm{mg}$ twice daily the day before and the day of the procedure [3] or with an i.v. dose of $150 \mathrm{mg} / \mathrm{kg}$ half an hour before the procedure or $50 \mathrm{mg} / \mathrm{kg}$ administered for 4 hours [151].

Conflicting results have been obtained with the use of the antioxidant ascorbic acid. Thus, some authors have demonstrated that prophylactic oral administration of ascorbic acid may protect against contrast-induced CIN [159-161] at a dosage of $3 \mathrm{~g}$ orally 2 hours before the procedure and $2 \mathrm{~g}$ during the night and in the morning after the procedure $[159,160]$. Other authors demonstrated a nonprotective effect [162]. In a recent meta-analysis, with 1536 patients who completed the trial, patients receiving ascorbic acid had a $33 \%$ less risk of developing CIN [161].

Three different methods for preventing CIN have been interestingly compared some years ago by Briguori et al. [163] in 326 patients with chronic kidney disease: $0.9 \%$ saline infusion $+\mathrm{N}$-acetylcysteine $(n=111)$, sodium bicarbonate infusion $+\mathrm{N}$-acetylcysteine $(n=108)$, and $0.9 \%$ saline + ascorbic acid $+\mathrm{N}$-acetylcysteine $(n=107)$. The mean amounts of contrast medium (iodixanol) administered were $179+/-102$, $169+/-92$, and $169+/-94 \mathrm{~mL}(P=0.69)$, respectively; and risk scores $(9.1+/-3.4,9.5+/-3.6$, and $9.3+/-3.6 ; P=0.21)$ were similar in the three groups. CIN occurred in 11 of 111 patients (9.9\%) after saline $+\mathrm{N}$-acetylcysteine, in 2 of $108(1.9 \%)$ after bicarbonate $+\mathrm{N}$-acetylcysteine, and in 11 of $107(10 \%)$ after saline + ascorbic acid $+\mathrm{N}$-acetylcysteine. The authors 
concluded that sodium bicarbonate $+\mathrm{N}$-acetylcysteine was superior to the other two methods.

In another study by Poletti et al. [164], out of 87 adults with renal insufficiency who underwent emergency CT scanning, 43 were hydrated and given $\mathrm{N}$-acetylcysteine $(900 \mathrm{mg}$ ) intravenously; the other 44 were only hydrated. There was a $25 \%$ or greater increase in serum creatinine concentration in two of the former and in nine of the latter. However, there was a $25 \%$ or greater increase in serum cystatin C concentration in seven and nine patients respectively. This disjunction between the effects of acetylcysteine on creatinine and cystatin levels led the authors to suggest that acetylcysteine might prevent the rise in serum creatinine after contrast administration without actually preventing CIN.

Tasanarong et al. [165] carried out a prospective, doubleblind, randomized and placebo-controlled trial in 305 patients with CRF undergoing coronary procedures with iopromide (LOCM). The oral administration of 2 antioxidants, either $350 \mathrm{mg} /$ day of $\alpha$-tocopherol or $300 \mathrm{mg} /$ day of $\gamma$ tocopherol (5 days prior to the procedure and continued for a further 2 days post-procedure) in combination with $0.9 \%$ saline $(1 \mathrm{~mL} / \mathrm{kg} / \mathrm{h}$ for 12 hours before and 12 hours after) was shown to protect against CIN: CIN occurred in $14.9 \%$ of cases in the placebo group, but only in $4.9 \%$ and $5.9 \%$ in the $\alpha$ - and $\gamma$-tocopherol groups, respectively.

Nebivolol, a third-generation $\beta_{1}$-adrenergic receptor antagonist, has been suggested for protecting kidney against CIN because its antioxidant and NO-mediated vasodilating action [166-168]: $5 \mathrm{mg} /$ day for one week or $5 \mathrm{mg}$ every 24 hours for 4 days have been shown to decrease the incidence of CIN in patients with renal dysfunction undergoing coronary angiography $[169,170]$.

Recent studies have shown a beneficial effect of statins in preventing $\mathrm{CIN}$ in patients undergoing percutaneous coronary intervention [171-176]. The nephroprotective effect of statins has been attributed to their antioxidant, anti-inflammatory, and antithrombotic properties and to their vasodilator property mediated by NO that improves renal microcirculation [177, 178]. Rosuvastatin, at a dosage of $10 \mathrm{mg} /$ day for five days, administered two days before and three days post the radiographic procedure, reduced the risk of CIN in patients with diabetes mellitus and CRF undergoing coronary/peripheral arterial angiography [179]. In patients with acute coronary syndrome, scheduled for an early invasive procedure, rosuvastatin, at a dosage of $40 \mathrm{mg}$ on admission followed by $20 \mathrm{mg} /$ day, has been shown to reduce the incidence of CIN [180]. Short-term atorvastatin $(40 \mathrm{mg} /$ day 3 days before the procedure) and chronic atorvastatin therapy had a protective effect on renal function after coronary angiography [181]. Short-term high-dose atorvastatin $(80 \mathrm{mg} 12$ hours before intervention with another $40 \mathrm{mg}$ preprocedure dose) has been shown to decrease the incidence of CIN in patients with acute coronary syndrome undergoing percutaneous coronary interventions [182]. These results suggest the early use of high-dose statins before percutaneous coronary revascularization to protect patients against contrast media nephrotoxicity.

\section{Other Protective Measures}

As mentioned above, enhanced transport activity in the outer renal medulla will increase oxygen consumption, thereby causing renal hypoxia, whose role is important in the pathogenesis of CIN. Thus, furosemide has been suggested for protecting the kidney by reducing the active tubular reabsorption. Furthermore, the consequent increase in urine output will decrease the contact time of contrast material with tubular epithelium, thereby reducing the epithelial damage. But the increase of urinary salt excretion with the diuretic may cause salt depletion in the absence of adequate fluid replacement. Thus, Marenzi et al. [183] have suggested the perfect combination of hydration plus furosemide: this was obtained by delivering i.v. fluid in an amount exactly matched to the volume of urine produced by the patient under the effect of furosemide: the result was a significantly lower incidence of CIN when compared to the patients treated with hydration only.

As mentioned above, the intracellular $\mathrm{Ca}^{2+}$ overload is considered to be a key factor in ischemic cell injury and in CIN. The increase in intracellular calcium provokes a vasoconstrictive response in intrarenal circulation and would be an important mediator of epithelial cell apoptosis and necrosis. Thus, calcium channel blockers have been hypothesized to have protective effects against CIN. Their use, however, has given controversial results, some authors suggesting them to be protective $[184,185]$, whilst others finding no benefit at all [44, 186-188].

Since urinary adenosine is increased after contrast media administration, it has been thought that adenosine antagonists, such as theophylline or aminophylline, could have protective effects against contrast media. Similarly also for these drugs their use has given controversial results, with some finding beneficial effects against CIN [189-192], whilst others finding no beneficial results $[193,194]$.

Plasma and urine levels of endothelin-1 are increased in diabetes and after exposure to high doses of contrast media; this has suggested a role of endothelin-1 in diabetic nephropathy and in CIN $[87,195,196]$. However, endothelin receptor blockers have been proven to be deleterious as a prophylactic tool against CIN [197].

Trimetazidine (TMZ) has been described as a cellular anti-ischemic agent [198]. Previous studies demonstrated that TMZ prevents the deleterious effects of ischaemia-reperfusion at both the cellular and the mitochondrial levels, and exerts potent antioxidant activity on various tissue preparations $[199,200]$. TMZ inhibits the excessive release of oxygen-free radicals, increases glucose metabolism, limits intracellular acidosis, protects ATP stores, reduces membrane lipid peroxidation and inhibits neutrophil infiltration after ischaemia-reperfusion. Onbasili et al. [201] studied the efficacy of TMZ in the prevention of CIN in 82 patients with high serum creatinine concentration undergoing coronary angiography/angioplasty. TMZ (20 mg thrice daily) was given orally for 72 hours starting 48 hours before the procedure and all the patients were given intravenous isotonic saline $(1 \mathrm{~mL} / \mathrm{kg})$ for 24 hours starting 12 hours beforehand. CIN developed in only one of 40 patients who were given TMZ 
(2.5\%) and in seven of 42 controls (17\%). The authors concluded that the administration of TMZ $(20 \mathrm{mg}$ thrice daily, orally) in conjunction with saline is an effective means for preventing transient renal dysfunction due to radiocontrast agent; they admitted several limitations of their study, such as the relatively small sample size investigated and the dose of oral TMZ that had been chosen for this study that was derived from the standard regimen for the treatment of myocardial ischaemia. In addition, relatively low-risk patients with mild renal insufficiency had been included in that study. The effect of TMZ on high-risk patients should be further investigated in larger prospective clinical studies to determine whether it can be useful for significantly preventing CIN.

Dopamine and dopamine agonists, such as fenoldopam, a selective dopamine-1 receptor agonist with vasodilatory properties, have given controversial results in protecting against CIN, some positive [202-204], others negative [153, 194, 205-207]. On the basis of our present knowledge, it is better to avoid these drugs because of their adverse effects (arrhythmia with dopamine, and systemic hypotension with intravenous fenoldopam).

Recombinant human erythropoietin (EPO; $200 \mathrm{U} / \mathrm{mL}$ ) has been also used by Kolyada et al. [208] in order to investigate the protection of renal tubular cells against contrast medium-induced injury in vitro in LLC-PK1 (a well-known non-human renal tubular epithelial cell line), which were exposed to a non-ionic low-osmolar agent iohexol and to the isoosmolar agent iodixanol for 6 hours: EPO improved the viability of the iohexol-treated cells by $27 \%$ and the viability of the iodixanol-treated cells by $26 \%$. It also reduced apoptosis rates and attenuated activation of caspase-3, caspase- 8 , and caspase-9.

Previously, Goldfarb et al. [209] had demonstrated that EPO pretreatment prevented renal dysfunction in a rat model of CIN, induced by iothalamate. EPO was given to male Sprague-Dawley rats (EPO group) at the dosage of $3000 \mathrm{U} / \mathrm{kg}$ and $600 \mathrm{U} / \mathrm{kg}, 24$ and $2 \mathrm{~h}$ before the induction of CIN, respectively. The decline in creatinine clearance in control (CTR group; subjected to saline) animals was prevented by EPO pre-treatment. The extent of medullary thick ascending limb- and S3-tubular damage in the outer renal medulla, however, was comparable in the two experimental groups ("CTR" and "EPO").

In another study by Yokomaku et al. [210], asialoerythropoietin, a nonhemopoietic derivative of erythropoietin, attenuated contrast-induced renal dysfunction and renal tubular damage in rats, an effect that was attributed to inhibition of apoptosis by activation of Janus kinase 2 (JAK2) and the phospho-JAK2/signal transducer and activator of transcription 5 (STAT5).

No clinical studies are available at the moment to confirm these experimental data in humans by demonstrating a protective role of EPO in patients subjected to CIN.

\section{Haemodialysis and Hemofiltration}

It has been suggested to remove radiocontrast media by hemodialysis or hemofiltration immediately after the radiographic procedure. Schindler et al. [211] demonstrated, in patients with CRF (most of whom in chronic dialysis), that different dialysis techniques do remove contrast media (iopromide or iomeprol), high-flux hemodialysis and hemodiafiltration more effectively than low-flux hemodialysis and hemofiltration. But Lehnert et al. [212] demonstrated that, although hemodialysis eliminates contrast media, it does not prevent CIN. Vogt et al. [213] performed a randomized trial to test whether CIN can be avoided by prophylactic hemodialysis immediately after the administration of lowosmolality contrast media in patients with impaired renal function (baseline serum creatinine level > $2.3 \mathrm{mg} / \mathrm{dL}$ ); renal function was recorded before and during the 6 days after administration of contrast media. The prophylactic hemodialysis did not diminish the rate of CIN. These results suggested that, even if dialysis is carried out immediately, the early damage has already triggered a cascade of pathogenic events, which cannot be reversed [214, 215].

It is worthwhile to point out that the European Renal Best Practice [113] does "not recommend using prophylactic intermittent hemodialysis or hemofiltration for the purpose of prevention of CIN."

\section{Conclusion}

To answer the initial question as to whether CIN is still a clinical problem, we may underline that today the incidence of CIN is less than it was in the past, provided that clinicians identify the patients at risk and use all the precautions listed above, particularly monitoring renal function before, during, and after the radiographic procedure and preventing dehydration and salt depletion. However, CIN is still too frequent in patients at high risk for contrast nephrotoxicity because of concomitant diseases such as diabetes mellitus with renal failure, severe congestive heart failure, reduction of "effective" circulating blood volume, sepsis. We do hope to significantly reduce the occurrence of CIN also in these patients with the development of newer and less toxic iodinated contrast media.
Abbreviations
CIN: Contrast-Induced nephropathy
CI-AKI: Contrast-induced acute kidney injury
ARF: Acute renal failure
CT: $\quad$ Computed tomography
i.v.: Intravenous
MDRD: Modification of diet in renal disease
CKD-EPI: Chronic kidney disease epidemiology collaboration
eGFR: Estimated glomerular filtration rate
RBF: Renal blood flow
GFR: Glomerular filtration rate
NO: $\quad$ Nitric oxide
$\mathrm{O}_{2}$ : Oxygen
ROS: $\quad$ Reactive oxygen species
HOCM: High-osmolar contrast media
LOCM: Low-osmolar contrast media
IOCM: Iso-osmolar contrast media
CRF: Chronic renal failure 
ACEIs: Angiotensin-converting enzyme inhibitors

ARBs: Angiotensin II receptor blockers

EPO: Erythropoietin

TMZ: Trimetazidine.

\section{Conflict of Interests}

The authors declare that there is no conflict of interests regarding the publication of this paper.

\section{Acknowledgment}

Dr. Ashour Michael is currently recipient of an "Assegno di Ricerca" (Research check) at the "Magna Graecia" University of Catanzaro (Italy).

\section{References}

[1] E. D. Bartels, G. C. Brun, A. Gammeltoft, and P. A. Gjorup, "Acute anuria following intravenous pyelography in a patient with myelomatosis," Acta Medica Scandinavica, vol. 150, pp. 297-302, 1954

[2] M. Mussap and G. Merlini, "Pathogenesis of renal failure in multiple myeloma: any role of contrast media?" BioMed Research International, vol. 2014, Article ID 167125, 10 pages, 2014.

[3] T. G. Gleeson and S. Bulugahapitiya, "Contrast-induced nephropathy," American Journal of Roentgenology, vol. 183, no. 6, pp. 1673-1689, 2004.

[4] F. G. Meinel, C. N. de Cecco, U. J. Schoepf, and R. Katzberg, "Contrast-induced acute kidney injury: definition, epidemiology, and outcome," BioMed Research International, vol. 2014, Article ID 859328, 6 pages, 2014.

[5] N. Berlyne and G. M. Berlyne, "Acute renal failure following intravenous pyelography with hypaque," Acta Medica Scandinavica, vol. 171, pp. 39-41, 1962.

[6] Q. A. Rao and J. H. Newhouse, "Risk of nephropathy after intravenous administration of contrast material: a critical literature analysis," Radiology, vol. 239, no. 2, pp. 392-397, 2006.

[7] B. M. Elicker, Y. S. Cypel, and J. C. Weinreb, "IV contrast administration for CT: a survey of practices for the screening prevention of contrast nephropathy," The American Journal of Roentgenology, vol. 186, no. 6, pp. 1651-1658, 2006.

[8] R. W. Katzberg and J. H. Newhouse, "Intravenous contrast medium-induced nephrotoxicity: is the medical risk really as great as we have come to believe?" Radiology, vol. 256, no. 1, pp. 21-28, 2010.

[9] A. S. Levey, J. P. Bosch, J. B. Lewis, T. Greene, N. Rogers, and D. Roth, "A more accurate method to estimate glomerular filtration rate from serum creatinine: a new prediction equation," Annals of Internal Medicine, vol. 130, no. 6, pp. 461-470, 1999.

[10] A. S. Levey, L. A. Stevens, C. H. Schmid et al., "A new equation to estimate glomerular filtration rate," Annals of Internal Medicine, vol. 150, no. 9, pp. 604-612, 2009.

[11] D. W. Cockcroft and M. H. Gault, "Prediction of creatinine clearance from serum creatinine," Nephron, vol. 16, no. 1, pp. 3141, 1976 .

[12] M. Andreucci, R. Solomon, and A. Tasanarong, "Side effects of radiographic contrast media: pathogenesis, risk factors, and prevention," BioMed Research International, vol. 2014, Article ID 741018, 20 pages, 2014.
[13] C. Briguori, A. Colombo, A. Violante et al., "Standard vs. double dose of $\mathrm{N}$-acetylcysteine to prevent contrast agent associated nephrotoxicity," European Heart Journal, vol. 25, no. 3, pp. 206211, 2004.

[14] V. E. Andreucci, G. Fuiano, D. Russo, and M. Andreucci, "Vasomotor nephropathy in the elderly," Nephrology Dialysis Transplantation, vol. 13, supplement 7, pp. 17-24, 1998.

[15] V. E. Andreucci, G. Fuiano, P. Stanziale, and M. Andreucci, "Role of renal biopsy in the diagnosis and prognosis of acute renal failure," Kidney International, Supplement, vol. 53, no. 66, pp. S91-S95, 1998.

[16] M. Andreucci, "Side effects of radiographic contrast media," BioMed Research International, vol. 2014, Article ID 872574, 2014.

[17] L. M. Curtis and A. Agarwal, "HOpe for contrast-induced acute kidney injury," Kidney International, vol. 72, no. 8, pp. 907-909, 2007.

[18] R. Solomon, "Contrast-induced acute kidney injury: is there a risk after intravenous contrast?" Clinical Journal of the American Society of Nephrology, vol. 3, no. 5, pp. 1242-1243, 2008.

[19] S. D. Weisbord and P. M. Palevsky, "Prevention of contrastinduced nephropathy with volume expansion," Clinical Journal of the American Society of Nephrology, vol. 3, no. 1, pp. 273-280, 2008.

[20] R. Mehran and E. Nikolsky, "Contrast-induced nephropathy: definition, epidemiology, and patients at risk," Kidney International. Supplement, pp. S11-S15, 2006.

[21] R. J. Bruce, A. Djamali, K. Shinki, S. J. Michel, J. P. Fine, and M. A. Pozniak, "Background fluctuation of kidney function versus contrast-induced nephrotoxicity," American Journal of Roentgenology, vol. 192, no. 3, pp. 711-718, 2009.

[22] R. J. McDonald, J. S. McDonald, J. P. Bida et al., "Intravenous contrast material-induced nephropathy: causal or coincident phenomenon?" Radiology, vol. 267, no. 1, pp. 106-118, 2013.

[23] J. S. McDonald, R. J. McDonald, J. Comin et al., "Frequency of acute kidney injury following intravenous contrast medium administration: a systematic review and meta-analysis," Radiology, vol. 267, no. 1, pp. 119-128, 2013.

[24] A. M. Mitchell, A. E. Jones, J. A. Tumlin, and J. A. Kline, "Incidence of contrast-induced nephropathy after contrastenhanced computed tomography in the outpatient setting," Clinical Journal of the American Society of Nephrology, vol. 5, no. 1, pp. 4-9, 2010.

[25] M. S. Davenport, S. Khalatbari, R. H. Cohan, J. R. Dillman, J. D. Myles, and J. H. Ellis, "Contrast material-induced nephrotoxicity and intravenous low-osmolality iodinated contrast material: risk stratification by using estimated glomerular filtration rate," Radiology, vol. 268, no. 3, pp. 719-728, 2013.

[26] M. S. Davenport, S. Khalatbari, J. R. Dillman, R. H. Cohan, E. M. Caoili, and J. H. Ellis, "Contrast material-induced nephrotoxicity and intravenous low-osmolality iodinated contrast material," Radiology, vol. 267, no. 1, pp. 94-105, 2013.

[27] M. Rudnick and H. Feldman, "Contrast-induced nephropathy: what are the true clinical consequences?" Clinical Journal of the American Society of Nephrology, vol. 3, no. 1, pp. 263-272, 2008.

[28] G. Fuiano, D. Mancuso, C. Indolfi et al., "Early detection of progressive renal dysfunction in patients with coronary artery disease," Kidney International, vol. 68, no. 6, pp. 2773-2780, 2005.

[29] R. J. Solomon, R. Mehran, M. K. Natarajan et al., "Contrastinduced nephropathy and long-term adverse events: cause and 
effect?" Clinical Journal of the American Society of Nephrology, vol. 4, no. 7, pp. 1162-1169, 2009.

[30] P. J. Scanlon, D. P. Faxon, A. M. Audet et al., "ACC/AHA guidelines for coronary angiography. A report of the American College of Cardiology/American Heart Association Task Force on practice guidelines (Committee on Coronary Angiography). Developed in collaboration with the Society for Cardiac Angiography and Interventions," Circulation, vol. 33, no. 6, pp. 1756-1824, 1999.

[31] S. W. Murphy, B. J. Barrett, and P. S. Parfrey, "Contrast nephropathy," Journal of the American Society of Nephrology, vol. 11, no. 1, pp. 177-182, 2000.

[32] S. N. Heyman, S. Rosen, and C. Rosenberger, "Renal parenchymal hypoxia, hypoxia adaptation, and the pathogenesis of radiocontrast nephropathy," Clinical Journal of the American Society of Nephrology, vol. 3, no. 1, pp. 288-296, 2008.

[33] A. M. Bucher, C. N. de Cecco, U. J. Schoepf et al., "Is contrast medium osmolality a causal factor for contrast-induced nephropathy?" BioMed Research International, vol. 2014, Article ID 931413, 8 pages, 2014.

[34] M. Andreucci, T. Faga, A. Pisani, M. Sabbatini, and A. Michael, "Acute kidney injury by radiographic contrast media: pathogenesis and prevention," BioMed Research International, vol. 2014, Article ID 362725, 21 pages, 2014.

[35] M. Andreucci, T. Faga, A. Pisani, M. Sabbatini, and A. Michael, "Pathogenesis of acute renal failure induced by iodinated radiographic contrast media," Austin Journal of Nephrology and Hypertension, vol. 1, no. 1, pp. 1-6, 2014.

[36] A. Pisani, E. Riccio, M. Andreucci et al., "Role of reactive oxygen species in pathogenesis of radiocontrast-induced nephropathy," BioMed Research International, vol. 2013, Article ID 868321, 6 pages, 2013.

[37] A. J. Giaccia, M. C. Simon, and R. Johnson, "The biology of hypoxia: the role of oxygen sensing in development, normal function, and disease," Genes and Development, vol. 18, no. 18, pp. 2183-2194, 2004.

[38] M. Sabbatini, M. Santillo, A. Pisani et al., "Inhibition of Ras/ ERK1/2 signaling protects against postischemic renal injury," American Journal of Physiology: Renal Physiology, vol. 290, no. 6, pp. F1408-F1415, 2006.

[39] S. N. Heyman, S. Rosen, M. Khamaisi, J.-M. Idée, and C. Rosenberger, "Reactive oxygen species and the pathogenesis of radiocontrast-induced nephropathy," Investigative Radiology, vol. 45, no. 4, pp. 188-195, 2010.

[40] P. Dawson, M. J. G. Harrison, and E. Weisblatt, "Effect of contrast media on red cell filtrability and morphology," British Journal of Radiology, vol. 56, no. 670, pp. 707-710, 1983.

[41] M. M. Sendeski, "Pathophysiology of renal tissue damage by iodinated contrast media," Clinical and Experimental Pharmacology and Physiology, vol. 38, no. 5, pp. 292-299, 2011.

[42] P. Pacher, J. S. Beckman, and L. Liaudet, "Nitric oxide and peroxynitrite in health and disease," Physiological Reviews, vol. 87, no. 1, pp. 315-424, 2007.

[43] A. Pisani, M. Sabbatini, E. Riccio et al., "Effect of a recombinant manganese superoxide dismutase on prevention of contrast-induced acute kidney injury," Clinical and Experimental Nephrology, vol. 18, no. 3, pp. 424-431, 2014.

[44] A. Caiazza, L. Russo, M. Sabbatini, and D. Russo, "Hemodynamic and tubular changes induced by contrast media," BioMed Research International, vol. 2014, Article ID 578974, 7 pages, 2014.
[45] C. Gospos, N. Freudenberg, J. Staubesand, K. Mathias, and X. Papacharlampos, "The effect of contrast media on the aortic endothelium of rats," Radiology, vol. 147, no. 3, pp. 685-688, 1983.

[46] K. Hardiek, R. E. Katholi, V. Ramkumar, and C. Deitrick, "Proximal tubule cell response to radiographic contrast media," The American Journal of Physiology—Renal Physiology, vol. 280, no. 1, pp. F61-F70, 2001.

[47] M. C. Heinrich, M. K. Kuhlmann, A. Grgic, M. Heckmann, B. Kramann, and M. Uder, "Cytotoxic effects of ionic highosmolar, nonionic monomeric, and nonionic iso-osmolar dimeric iodinated contrast media on renal tubular cells in vitro," Radiology, vol. 235, no. 3, pp. 843-849, 2005.

[48] A. Michael, T. Faga, A. Pisani et al., "Molecular mechanisms of renal cellular nephrotoxicity due to radiocontrast media," BioMed Research International, vol. 2014, Article ID 249810, 10 pages, 2014.

[49] M. Andreucci, A. Michael, C. Kramers et al., "Renal ische$\mathrm{mia} /$ reperfusion and ATP depletion/repletion in LLC-PK 1 cells result in phosphorylation of FKHR and FKHRL1," Kidney International, vol. 64, no. 4, pp. 1189-1198, 2003.

[50] M. Andreucci, G. Fuiano, P. Presta et al., "Downregulation of cell survival signalling pathways and increased cell damage in hydrogen peroxide-treated human renal proximal tubular cells by alpha-erythropoietin," Cell Proliferation, vol. 42, no. 4, pp. 554-561, 2009.

[51] M. Andreucci, "Contrast media and nephrotoxicity: a molecular conundrum," Giornale Italiano di Nefrologia, vol. 28, no. 4, article 355, 2011.

[52] C. Quintavalle, M. Brenca, F. de Micco et al., "In vivo and in vitro assessment of pathways involved in contrast mediainduced renal cells apoptosis," Cell Death and Disease, vol. 2, no. 5, article e155, 2011.

[53] M. Andreucci, T. Faga, G. Lucisano et al., "Mycophenolic acid inhibits the phosphorylation of NF- $\kappa \mathrm{B}$ and JNKs and causes a decrease in IL-8 release in $\mathrm{H}_{2} \mathrm{O}_{2}$-treated human renal proximal tubular cells," Chemico-Biological Interactions, vol. 185, no. 3, pp. 253-262, 2010.

[54] M. Andreucci, G. Fuiano, P. Presta et al., "Radiocontrast media cause dephosphorylation of Akt and downstream signaling targets in human renal proximal tubular cells," Biochemical Pharmacology, vol. 72, no. 10, pp. 1334-1342, 2006.

[55] M. Andreucci, T. Faga, D. Russo et al., "Differential activation of signaling pathways by low-osmolar and Iso-osmolar radiocontrast agents in human renal tubular cells," Journal of Cellular Biochemistry, vol. 115, no. 2, pp. 281-289, 2014.

[56] M. Andreucci, G. Lucisano, T. Faga et al., "Differential activation of signaling pathways involved in cell death, survival and inflammation by radiocontrast media in human renal proximal tubular cells," Toxicological Sciences, vol. 119, no. 2, pp. 408-416, 2011.

[57] H.-C. Lee, J.-G. Chang, H.-W. Yen, I.-H. Liu, W.-T. Lai, and S.-H. Sheu, "Ionic contrast media induced more apoptosis in diabetic kidney than nonionic contrast media," Journal of Nephrology, vol. 24, no. 3, pp. 376-380, 2011.

[58] M. A. Cunha and N. Schor, "Effects of gentamicin, lipopolysaccharide, and contrast media on immortalized proximal tubular cells," Renal Failure, vol. 24, no. 5, pp. 655-658, 2002.

[59] A. Peer, Z. Averbukh, S. Berman, D. Modai, M. Averbukh, and J. Weissgarten, "Contrast media augmented apoptosis of cultured renal mesangial, tubular, epithelial, endothelial, and hepatic cells," Investigative Radiology, vol. 38, no. 3, pp. 177-182, 2003. 
[60] D. Yang, D. Yang, R. Jia, and J. Tan, "Na+/Ca2+ exchange inhibitor, KB-R7943, attenuates contrast-induced acute kidney injury," Journal of Nephrology, vol. 26, no. 5, pp. 877-885, 2013.

[61] S.-B. Duan, F.-Y. Liu, J.-A. Luo et al., "Nephrotoxicity of highand low-osmolar contrast media: the protective role of amlodipine in a rat model," Acta Radiologica, vol. 41, no. 5, pp. 503-507, 2000.

[62] D. Yang and D. Yang, "Role of intracellular $\mathrm{Ca}^{2+}$ and $\mathrm{Na}^{+} / \mathrm{Ca}^{2+}$ exchanger in the pathogenesis of contrast-induced acute kidney injury," BioMed Research International, vol. 2013, Article ID 678456, 5 pages, 2013.

[63] E. Seeliger, D. C. Lenhard, and P. B. Persson, "Contrast media viscosity versus osmolality in kidney injury: lessons from animal studies," BioMed Research International, vol. 2014, Article ID 358136, 15 pages, 2014.

[64] P. Aspelin, P. E. Nilsson, H. Schmid-Schönbein, S. Schröder, and R. Simon, "Effect of four non-ionic contrast media on red blood cells in vitro. III. Deformability," Acta Radiologica, vol. 370, pp. 89-91, 1987.

[65] M. R. Hardeman, P. Goedhart, and I. Y. Koen, "The effect of lowosmolar ionic and nonionic contrast media on human blood viscosity, erythrocyte morphology, and aggregation behavior," Investigative Radiology, vol. 26, no. 9, pp. 810-819, 1991.

[66] R. P. Franke, T. Scharnweber, R. Fuhrmann et al., "Effect of radiographic contrast media on the spectrin/band3-network of the membrane skeleton of erythrocytes," PLoS ONE, vol. 9, Article ID e89512, 2014.

[67] R. W. Katzberg, "Urography into the 21st century: new contrast media, renal handling, imaging characteristics, and nephrotoxicity," Radiology, vol. 204, no. 2, pp. 297-312, 1997.

[68] P. Aspelin, P. Aubry, S.-G. Fransson, R. Strasser, R. Willenbrock, and K. J. Berg, "Nephrotoxic effects in high-risk patients undergoing angiography," The New England Journal of Medicine, vol. 348, no. 6, pp. 491-499, 2003.

[69] C. P. Taliercio, R. E. Vlietstra, D. M. Ilstrup et al., "A randomized comparison of the nephrotoxicity of iopamidol and diatrizoate in high risk patients undergoing cardiac angiography," Journal of the American College of Cardiology, vol. 17, no. 2, pp. 384-390, 1991.

[70] B. J. Barrett and E. J. Carlisle, "Metaanalysis of the relative nephrotoxicity of high- and low-osmolality iodinated contrast media," Radiology, vol. 188, no. 1, pp. 171-178, 1993.

[71] B. J. Barrett, "Contrast nephrotoxicity," Journal of the American Society of Nephrology, vol. 5, no. 2, pp. 125-137, 1994.

[72] M. C. Heinrich, L. Häberle, V. Müller, W. Bautz, and M. Uder, "Nephrotoxicity of iso-osmolar iodixanol compared with nonionic low-osmolar contrast media: meta-analysis of randomized controlled trials," Radiology, vol. 250, no. 1, pp. 68-86, 2009.

[73] R. J. Solomon, M. K. Natarajan, S. Doucet et al., "Cardiac angiography in renally impaired patients (CARE) study: a randomized double-blind trial of contrast-induced nephropathy in patients with chronic kidney disease," Circulation, vol. 115, no. 25, pp. 3189-3196, 2007.

[74] M. Reed, P. Meier, U. U. Tamhane, K. B. Welch, M. Moscucci, and H. S. Gurm, "The relative renal safety of iodixanol compared with low-osmolar contrast media: a meta-analysis of randomized controlled trials," JACC: Cardiovascular Interventions, vol. 2, no. 7, pp. 645-654, 2009.

[75] L. Bolognese, G. Falsini, C. Schwenke et al., "Impact of isoosmolar versus low-osmolar contrast agents on contrastinduced nephropathy and tissue reperfusion in unselected patients with ST-segment elevation myocardial infarction undergoing primary percutaneous coronary intervention (from the Contrast Media and Nephrotoxicity Following primary Angioplasty for Acute Myocardial Infarction [CONTRASTAMI] trial)," The American Journal of Cardiology, vol. 109, no. 1, pp. 67-74, 2012.

[76] N. Chalmers and R. W. Jackson, "Comparison of iodixanol and iohexol in renal impairment," British Journal of Radiology, vol. 72, pp. 701-703, 1999.

[77] M. Dong, Z. Jiao, T. Liu, F. Guo, and G. Li, "Effect of administration route on the renal safety of contrast agents: a meta-analysis of randomized controlled trials," Journal of Nephrology, vol. 25, no. 3, pp. 290-301, 2012.

[78] G. Jost, H. Pietsch, J. Sommer et al., "Retention of iodine and expression of biomarkers for renal damage in the kidney after application of iodinated contrast media in rats," Investigative Radiology, vol. 44, no. 2, pp. 114-123, 2009.

[79] K. Dyvik, K. Dyrstad, and A. Tronstad, "Relationship between viscosity and determined injection pressure in angiography catheters for common roentgen contrast media," Acta Radiologica. Supplementum, vol. 399, pp. 43-49, 1995.

[80] M. C. Martín-Mateo, M. Sánchez-Portugal, S. Iglesias, A. de Paula, and J. Bustamante, "Oxidative stress in chronic renal failure," Renal Failure, vol. 21, no. 2, pp. 155-167, 1999.

[81] D. M. Okamura, S. Pennathur, K. Pasichnyk et al., "CD36 regulates oxidative stress and inflammation in hypercholesterolemic CKD," Journal of the American Society of Nephrology, vol. 20, no. 3, pp. 495-505, 2009.

[82] K. J. Hardiek, R. E. Katholi, R. S. Robbs, and C. E. Katholi, "Renal effects of contrast media in diabetic patients undergoing diagnostic or interventional coronary angiography," Journal of Diabetes and its Complications, vol. 22, no. 3, pp. 171-177, 2008.

[83] S. N. Heyman, C. Rosenberger, S. Rosen, and M. Khamaisi, "Why is diabetes mellitus a risk factor for contrast-induced nephropathy?" BioMed Research International, vol. 2013, Article ID 123589, 8 pages, 2013.

[84] S. Morabito, V. Pistolesi, G. Benedetti et al., "Incidence of contrast-induced acute kidney injury associated with diagnostic or interventional coronary angiography," Journal of Nephrology, vol. 25, no. 6, pp. 1098-1107, 2012.

[85] M. R. Rudnick, S. Goldfarb, and J. Tumlin, "Contrast-induced nephropathy: is the picture any clearer?" Clinical Journal of the American Society of Nephrology, vol. 3, no. 1, pp. 261-262, 2008.

[86] O. Toprak, M. Cirit, M. Yesil et al., "Impact of diabetic and prediabetic state on development of contrast-induced nephropathy in patients with chronic kidney disease," Nephrology Dialysis Transplantation, vol. 22, no. 3, pp. 819-826, 2007.

[87] M. Khamaisi, I. Raz, V. Shilo et al., "Diabetes and radiocontrast media increase endothelin converting enzyme-1 in the kidney," Kidney International, vol. 74, no. 1, pp. 91-100, 2008.

[88] A. Pflueger, T. S. Larson, K. A. Nath, B. F. King, J. M. Gross, and F. G. Knox, "Role of adenosine in contrast media-induced acute renal failure in diabetes mellitus," Mayo Clinic Proceedings, vol. 75, no. 12, pp. 1275-1283, 2000.

[89] H. S. Thomsen and S. K. Morcos, "Contrast media and the kidney: European Society of Urogenital Radiology (ESUR) guidelines," The British Journal of Radiology, vol. 76, no. 908, pp. 513-518, 2003.

[90] S. K. Morcos, H. S. Thomsen, and J. A. W. Webb, "Contrastmedia-induced nephrotoxicity: a consensus report," European Radiology, vol. 9, no. 8, pp. 1602-1613, 1999. 
[91] V. E. Andreucci, D. Russo, B. Cianciaruso, and M. Andreucci, "Some sodium, potassium and water changes in the elderly and their treatment," Nephrology Dialysis Transplantation, vol. 11, no. 9, pp. 9-17, 1996.

[92] M. Andreucci, "Radiographic contrast nephropathy," Giornale Italiano di Nefrologia, vol. 31, no. 5, 2014 (Italian).

[93] M. Andreucci, S. Federico, and V. E. Andreucci, "Edema and acute renal failure," Seminars in Nephrology, vol. 21, no. 3, pp. 251-256, 2001.

[94] E. Seeliger, B. Flemming, T. Wronski et al., "Viscosity of contrast media perturbs renal hemodynamics," Journal of the American Society of Nephrology, vol. 18, no. 11, pp. 2912-2920, 2007.

[95] S. T. Cochran, W. S. Wong, and D. J. Roe, "Predicting angiography-induced acute renal function impairment: clinical risk model," The American Journal of Roentgenology, vol. 141, no. 5, pp. 1027-1033, 1983.

[96] E. Nikolsky, R. Mehran, Z. Lasic et al., "Low hematocrit predicts contrast-induced nephropathy after percutaneous coronary interventions," Kidney International, vol. 67, no. 2, pp. 706-713, 2005.

[97] A. Kolonko, F. Kokot, and A. Więcek, "Contrast-associated nephropathy-old clinical problem and new therapeutic perspectives," Nephrology Dialysis Transplantation, vol. 13, no. 3, pp. 803-806, 1998.

[98] T. S. Ahuja, N. Niaz, and M. Agraharkar, "Contrast-induced nephrotoxicity in renal allograft recipients," Clinical Nephrology, vol. 54, no. 1, pp. 11-14, 2000.

[99] M. Ranucci, A. Ballotta, A. Kunkl et al., "Influence of the timing of cardiac catheterization and the amount of contrast media on acute renal failure after cardiac surgery," The American Journal of Cardiology, vol. 101, no. 8, pp. 1112-1118, 2008.

[100] R. Kalyesubula, P. Bagasha, and M. A. Perazella, "ACE-I/ARB therapy prior to contrast exposure: what should the clinician do?" BioMed Research International, vol. 2014, Article ID 423848, 7 pages, 2014.

[101] J. A. Neyra, S. Shah, R. Mooney, G. Jacobsen, J. Yee, and J. E. Novak, "Contrast-induced acute kidney injury following coronary angiography: a cohort study of hospitalized patients with or without chronic kidney disease," Nephrology Dialysis Transplantation, vol. 28, no. 6, pp. 1463-1471, 2013.

[102] A. C. Schoolwerth, D. A. Sica, B. J. Ballermann, and C. S. Wilcox, "Renal considerations in angiotensin converting enzyme inhibitor therapy: a statement for healthcare professionals from the council on the kidney in cardiovascular disease and the council for high blood pressure research of the american heart association," Circulation, vol. 104, no. 16, pp. 1985-1991, 2001.

[103] M. Cirit, O. Toprak, M. Yesil et al., "Angiotensin-converting enzyme inhibitors as a risk factor for contrast-induced nephropathy," Nephron Clinical Practice, vol. 104, no. 1, pp. c20-c27, 2006.

[104] D. Kiski, W. Stepper, E. Brand, G. Breithardt, and H. Reinecke, "Impact of renin-angiotensin-aldosterone blockade by angiotensin-converting enzyme inhibitors or AT-1 blockers on frequency of contrast medium-induced nephropathy: a posthoc analysis from the Dialysis-versus-Diuresis (DVD) trial," Nephrology Dialysis Transplantation, vol. 25, no. 3, pp. 759-764, 2010.

[105] M. Y. Rim, H. Ro, W. C. Kang et al., "The effect of reninangiotensin-aldosterone system blockade on contrast-induced acute kidney injury: a propensity-matched study," The American Journal of Kidney Diseases, vol. 60, no. 4, pp. 576-582, 2012.
[106] Z. Umruddin, K. Moe, and K. Superdock, "ACE inhibitor or angiotensin II receptor blocker use is a risk factor for contrastinduced nephropathy," Journal of Nephrology, vol. 25, no. 5, pp. 776-781, 2012.

[107] M. A. C. Onuigbo and N. T. C. Onuigbo, "Does renin-angiotensin aldosterone system blockade exacerbate contrastinduced nephropathy in patients with chronic kidney disease? A prospective 50-month mayo clinic study," Renal Failure, vol. 30, no. 1, pp. 67-72, 2008.

[108] KDIGOKAKIW Group, "KDIGO clinical practice guideline for acute kidney injury," Kidney International Supplements, vol. 2, no. 1, pp. 1-138, 2012.

[109] M. Andreucci, T. Faga, M. Sabbatini, A. Pisani, D. Russo, and A. Michael, "How to prevent Contrast-Induced Nephropathy in clinical practice," Journal of Clinical Nephrology and Research, vol. 1, no. 1, article 1002, 12 pages, 2014.

[110] P. Susantitaphong and S. Eiam-Ong, "Nonpharmacological strategies to prevent contrast-induced acute kidney injury," BioMed Research International, vol. 2014, Article ID 463608, 12 pages, 2014.

[111] R. Solomon, "Contrast media: are there differences in nephrotoxicity among contrast media?" BioMed Research International, vol. 2014, Article ID 934947, 8 pages, 2014.

[112] P. Pattharanitima and A. Tasanarong, "Pharmacological strategies to prevent contrast-induced acute kidney injury," BioMed Research International, vol. 2014, Article ID 236930, 21 pages, 2014.

[113] D. Fliser, M. Laville, A. Covic et al., "A European Renal Best Practice (ERBP) position statement on the Kidney Disease Improving Global Outcomes (KDIGO) Clinical Practice Guidelines on Acute Kidney Injury: part 1: definitions, conservative management and contrast-induced nephropathy," Nephrology Dialysis Transplantation, vol. 27, no. 12, pp. 4263-4272, 2012.

[114] K. Thomson, "Safe use of radiographic contrast media," Australian Prescriber, vol. 33, no. 1, pp. 19-22, 2010.

[115] C. Mueller, "Prevention of contrast-induced nephropathy with volume supplementation," Kidney International, vol. 69, pp. S16-S19, 2006.

[116] C. E. A. Balemans, L. J. M. Reichert, B. I. H. van Schelven, J. A. J. G. van Den Brand, and J. F. M. Wetzels, "Epidemiology of contrast material-induced nephropathy in the era of hydration," Radiology, vol. 263, no. 3, pp. 706-713, 2012.

[117] H. S. Thomsen, "Guidelines for contrast media from the European Society of Urogenital Radiology," American Journal of Roentgenology, vol. 181, no. 6, pp. 1463-1471, 2003.

[118] J. H. Ellis and R. H. Cohan, "Prevention of contrast-induced nephropathy: an overview," Radiologic Clinics of North America, vol. 47, no. 5, pp. 801-811, 2009.

[119] R. Solomon and H. L. Dauerman, "Contrast-induced acute kidney injury," Circulation, vol. 122, no. 23, pp. 2451-2455, 2010.

[120] G. J. Merten, W. P. Burgess, L. V. Gray et al., "Prevention of contrast-induced nephropathy with sodium bicarbonate: a randomized controlled trial," The Journal of the American Medical Association, vol. 291, no. 19, pp. 2328-2334, 2004.

[121] M. Masuda, T. Yamada, T. Mine et al., "Comparison of usefulness of sodium bicarbonate versus sodium chloride to prevent contrast-induced nephropathy in patients undergoing an emergent coronary procedure," The American Journal of Cardiology, vol. 100, no. 5, pp. 781-786, 2007. 
[122] E. E. Ozcan, S. Guneri, B. Akdeniz et al., "Sodium bicarbonate, $\mathrm{N}$-acetylcysteine, and saline for prevention of radiocontrastinduced nephropathy. A comparison of 3 regimens for protecting contrast-induced nephropathy in patients undergoing coronary procedures. A single-center prospective controlled trial," American Heart Journal, vol. 154, no. 3, pp. 539-544, 2007.

[123] S. D. Navaneethan, S. Singh, S. Appasamy, R. E. Wing, and A. R. Sehgal, "Sodium bicarbonate therapy for prevention of contrastinduced nephropathy: a systematic review and meta-analysis," American Journal of Kidney Diseases, vol. 53, no. 4, pp. 617-627, 2009.

[124] A. Tamura, Y. Goto, K. Miyamoto et al., "Efficacy of single-bolus administration of sodium bicarbonate to prevent contrastinduced nephropathy in patients with mild renal insufficiency undergoing an elective coronary procedure," The American Journal of Cardiology, vol. 104, no. 7, pp. 921-925, 2009.

[125] E. A. J. Hoste, J. J. De Waele, S. A. Gevaert, S. Uchino, and J. A. Kellum, "Sodium bicarbonate for prevention of contrastinduced acute kidney injury: a systematic review and metaanalysis," Nephrology Dialysis Transplantation, vol. 25, no. 3, pp. 747-758, 2010.

[126] M. Joannidis, M. Schmid, and C. J. Wiedermann, "Prevention of contrast media-induced nephropathy by isotonic sodium bicarbonate: a meta-analysis," Wiener Klinische Wochenschrift, vol. 120, no. 23-24, pp. 742-748, 2008.

[127] F. Assadi, "Acetazolamide for prevention of contrast-induced nephropathy: a new use for an old drug," Pediatric Cardiology, vol. 27, no. 2, pp. 238-242, 2006.

[128] M. Pakfetrat, M. H. Nikoo, L. Malekmakan et al., "A comparison of sodium bicarbonate infusion versus normal saline infusion and its combination with oral acetazolamide for prevention of contrast-induced nephropathy: a randomized, double-blind trial," International Urology and Nephrology, vol. 41, no. 3, pp. 629-634, 2009.

[129] J. S. Jang, H. Y. Jin, J. S. Seo et al., "Sodium bicarbonate therapy for the prevention of contrast-induced acute kidney injury-a systematic review and meta-analysis," Circulation Journal, vol. 76, no. 9, pp. 2255-2265, 2012.

[130] D. Reddan, M. Laville, and V. D. Garovic, "Contrast-induced nephropathy and its prevention: what do we really know from evidence-based findings?" Journal of Nephrology, vol. 22, no. 3, pp. 333-351, 2009.

[131] S. Zoungas, T. Ninomiya, R. Huxley et al., "Systematic review: sodium bicarbonate treatment regimens for the prevention of contrast-induced nephropathy," Annals of Internal Medicine, vol. 151, no. 9, pp. 631-638, 2009.

[132] W. P. Burgess and P. J. Walker, "Mechanisms of contrastinduced nephropathy reduction for saline $(\mathrm{NaCl})$ and sodium bicarbonate $\left(\mathrm{NaHCO}_{3}\right)$," BioMed Research International, vol. 2014, Article ID 510385, 6 pages, 2014.

[133] S. S. Brar, A. Y.-J. Shen, M. B. Jorgensen et al., "Sodium bicarbonate vs sodium chloride for the prevention of contrast medium-induced nephropathy in patients undergoing coronary angiography: a randomized trial," JAMA-Journal of the American Medical Association, vol. 300, no. 9, pp. 1038-1046, 2008.

[134] S. S. Brar, S. Hiremath, G. Dangas, R. Mehran, S. K. Brar, and M. B. Leon, "Sodium bicarbonate for the prevention of contrast induced-acute kidney injury: a systematic review and metaanalysis," Clinical Journal of the American Society of Nephrology, vol. 4, no. 10, pp. 1584-1592, 2009.
[135] L. Shavit, R. Korenfeld, M. Lifschitz, A. Butnaru, and I. Slotki, "Sodium bicarbonate versus sodium chloride and oral Nacetylcysteine for the prevention of contrast-induced nephropathy in advanced chronic kidney disease," Journal of Interventional Cardiology, vol. 22, no. 6, pp. 556-563, 2009.

[136] A. Vasheghani-Farahani, G. Sadigh, S. E. Kassaian et al., "Sodium bicarbonate plus isotonic saline versus saline for prevention of contrast-induced nephropathy in patients undergoing coronary angiography: a randomized controlled trial," American Journal of Kidney Diseases, vol. 54, no. 4, pp. 610-618, 2009.

[137] D. B. G. Oliveira, "Prophylaxis against contrast-induced nephropathy," The Lancet, vol. 353, no. 9165, pp. 1638-1639, 1999.

[138] P. A. McCullough, R. Wolyn, L. L. Rocher, R. N. Levin, and W. W. O'Neill, "Acute renal failure after coronary intervention: incidence, risk factors, and relationship to mortality," The American Journal of Medicine, vol. 103, no. 5, pp. 368-375, 1997.

[139] C. P. Taliercio, R. E. Vlietstra, L. D. Fisher, and J. C. Burnett, "Risks for renal dysfunction with cardiac angiography," Annals of Internal Medicine, vol. 104, no. 4, pp. 501-504, 1986.

[140] P. McCullough, "Outcomes of contrast-induced nephropathy: experience in patients undergoing cardiovascular intervention," Catheterization and Cardiovascular Interventions, vol. 67, no. 3, pp. 335-343, 2006.

[141] K. Kato, N. Sato, T. Yamamoto, Y.-K. Iwasaki, K. Tanaka, and K. Mizuno, "Valuable markers for contrast-induced nephropathy in patients undergoing cardiac catheterization," Circulation Journal, vol. 72, no. 9, pp. 1499-1505, 2008.

[142] M. Nunag, M. Brogan, and R. Garrick, "Mitigating contrastinduced acute kidney injury associated with cardiac catheterization," Cardiology in Review, vol. 17, no. 6, pp. 263-269, 2009.

[143] J. J. Keaney, C. M. Hannon, and P. T. Murray, "Contrast-induced acute kidney injury: how much contrast is safe?" Nephrology Dialysis Transplantation, vol. 28, no. 6, pp. 1376-1383, 2013.

[144] R. G. Cigarroa, R. A. Lange, R. H. Williams, and D. Hillis, "Dosing of contrast material to prevent contrast nephropathy in patients with renal disease," The American Journal of Medicine, vol. 86, no. C, pp. 649-652, 1989.

[145] W. K. Laskey, C. Jenkins, F. Selzer et al., "Volume-to-creatinine clearance ratio: a pharmacokinetically based risk factor for prediction of early creatinine increase after percutaneous coronary intervention," Journal of the American College of Cardiology, vol. 50, no. 7, pp. 584-590, 2007.

[146] H. S. Gurm, S. R. Dixon, D. E. Smith et al., "Renal functionbased contrast dosing to define safe limits of radiographic contrast media in patients undergoing percutaneous coronary interventions," Journal of the American College of Cardiology, vol. 58, no. 9, pp. 907-914, 2011.

[147] R. Safirstein, L. Andrade, and J. M. Vieira, "Acetylcysteine and nephrotoxic effects of radiographic contrast agents-a new use for an old drug," The New England Journal of Medicine, vol. 343, no. 3, pp. 210-212, 2000.

[148] H.-C. Lee, S.-H. Sheu, I.-H. Liu et al., "Impact of short-duration administration of $\mathrm{N}$-acetylcysteine, probucol and ascorbic acid on contrast-induced cytotoxicity," Journal of Nephrology, vol. 25, no. 1, pp. 56-62, 2012.

[149] A. M. From, B. J. Bartholmai, A. W. Williams, S. S. Cha, A. Pflueger, and F. S. McDonald, "Sodium bicarbonate is associated with an increased incidence of contrast nephropathy: a retrospective cohort study of 7977 patients at Mayo Clinic," Clinical Journal of the American Society of Nephrology, vol. 3, no. 1, pp. 10-18, 2008. 
[150] M. Tepel, M. van der Giet, C. Schwarzfeld, U. Laufer, D. Liermann, and W. Zidek, "Prevention of radiographic-contrastagent-induced reductions in renal function by acetylcysteine," The New England Journal of Medicine, vol. 343, no. 3, pp. 180$184,2000$.

[151] C. S. R. Baker, A. Wragg, S. Kumar, R. de Palma, L. R. I. Baker, and C. J. Knight, "A rapid protocol for the prevention of contrast-induced renal dysfunction: the RAPPID study," Journal of the American College of Cardiology, vol. 41, no. 12, pp. 2114-2118, 2003.

[152] J. D. Durham, C. Caputo, J. Dokko et al., "A randomized controlled trial of $\mathrm{N}$-acetylcysteine to prevent contrast nephropathy in cardiac angiography," Kidney International, vol. 62, no. 6, pp. 2202-2207, 2002.

[153] S. Allaqaband, R. Tumuluri, A. M. Malik et al., "Prospective randomized study of $\mathrm{N}$-acetylcysteine, fenoldopam, and saline for prevention of radiocontrast-induced nephropathy," Catheterization and Cardiovascular Interventions, vol. 57, no. 3 , pp. 279-283, 2002.

[154] I. Goldenberg, M. Shechter, S. Matetzky et al., "Oral acetylcysteine as an adjunct to saline hydration for the prevention of contrast-induced nephropathy following coronary angiography: a randomized controlled trial and review of the current literature," European Heart Journal, vol. 25, no. 3, pp. 212-218, 2004.

[155] N. Pannu, B. Manns, H. Lee, and M. Tonelli, "Systematic review of the impact of $\mathrm{N}$-acetylcysteine on contrast nephropathy," Kidney International, vol. 65, no. 4, pp. 1366-1374, 2004.

[156] L. C. Coyle, A. Rodriguez, R. E. Jeschke, A. Simon-Lee, K. C. Abbott, and A. J. Taylor, "Acetylcysteine In Diabetes (AID): a randomized study of acetylcysteine for the prevention of contrast nephropathy in diabetics," The American Heart Journal, vol. 151, no. 5, pp. 1032.e9-1032.e12, 2006.

[157] F. Ferrario, M. T. Barone, G. Landoni et al., "Acetylcysteine and non-ionic isosmolar contrast-induced nephropathy-a randomized controlled study," Nephrology Dialysis Transplantation, vol. 24, no. 10, pp. 3103-3107, 2009.

[158] H. S. Gurm, D. E. Smith, O. Berwanger et al., "Contemporary use and effectiveness of $\mathrm{N}$-acetylcysteine in preventing contrast-induced nephropathy among patients undergoing percutaneous coronary intervention," JACC: Cardiovascular Interventions, vol. 5, no. 1, pp. 98-104, 2012.

[159] K. Spargias, E. Alexopoulos, S. Kyrzopoulos et al., "Ascorbic acid prevents contrast-mediated nephropathy in patients with renal dysfunction undergoing coronary angiography or intervention," Circulation, vol. 110, no. 18, pp. 2837-2842, 2004.

[160] E. Alexopoulos, K. Spargias, S. Kyrzopoulos et al., "Contrastinduced acute kidney injury in patients with renal dysfunction undergoing a coronary procedure and receiving non-ionic lowosmolar versus iso-osmolar contrast media," The American Journal of the Medical Sciences, vol. 339, no. 1, pp. 25-30, 2010.

[161] U. Sadat, A. Usman, J. H. Gillard, and J. R. Boyle, "Does ascorbic acid protect against contrast-induced acute kidney injury in patients undergoing coronary angiography: a systematic review with meta-analysis of randomized, controlled trials," Journal of the American College of Cardiology, vol. 62, no. 23, pp. 2167-2175, 2013.

[162] A. Boscheri, C. Weinbrenner, B. Botzek, K. Reynen, E. Kuhlisch, and R. H. Strasser, "Failure of ascorbic acid to prevent contrastmedia induced nephropathy in patients with renal dysfunction," Clinical Nephrology, vol. 68, no. 5, pp. 279-286, 2007.
[163] C. Briguori, F. Airoldi, D. D’Andrea et al., "Renal insufficiency following contrast media administration trial (REMEDIAL): a randomized comparison of 3 preventive strategies," Circulation, vol. 115, no. 10, pp. 1211-1217, 2007.

[164] P.-A. Poletti, P. Saudan, A. Platon et al., "IV N-acetylcysteine and emergency CT: use of serum creatinine and cystatin $\mathrm{C}$ as markers of radiocontrast nephrotoxicity," American Journal of Roentgenology, vol. 189, no. 3, pp. 687-692, 2007.

[165] A. Tasanarong, A. Vohakiat, P. Hutayanon, and D. Piyayotai, "New strategy of $\alpha$-and $\gamma$-tocopherol to prevent contrastinduced acute kidney injury in chronic kidney disease patients undergoing elective coronary procedures," Nephrology Dialysis Transplantation, vol. 28, no. 2, pp. 337-344, 2013.

[166] A. Veverka, D. S. Nuzum, and J. L. Jolly, "Nebivolol: a thirdgeneration $\beta$-adrenergic blocker," Annals of Pharmacotherapy, vol. 40, no. 7-8, pp. 1353-1360, 2006.

[167] S. S. Sule and W. Frishman, "Nebivolol: new therapy update," Cardiology in Review, vol. 14, no. 5, pp. 259-264, 2006.

[168] O. Toprak, M. Cirit, M. Tanrisev et al., "Preventive effect of nebivolol on contrast-induced nephropathy in rats," Nephrology Dialysis Transplantation, vol. 23, no. 3, pp. 853-859, 2008.

[169] E. Avci, M. Yeşil, S. Bayata, N. Postaci, E. Arikan, and M. Cirit, "The role of nebivolol in the prevention of contrast-induced nephropathy in patients with renal dysfunction," Anadolu Kardiyoloji Dergisi, vol. 11, no. 7, pp. 613-617, 2011.

[170] Ö. Günebakmaz, M. G. Kaya, F. Koc et al., "Does nebivolol prevent contrast-induced nephropathy in humans?" Clinical Cardiology, vol. 35, no. 4, pp. 250-254, 2012.

[171] S. Khanal, N. Attallah, D. E. Smith et al., "Statin therapy reduces contrast-induced nephropathy: an analysis of contemporary percutaneous interventions," The American Journal of Medicine, vol. 118, no. 8, pp. 843-849, 2005.

[172] G. Patti, A. Nusca, M. Chello et al., "Usefulness of statin pretreatment to prevent contrast-induced nephropathy and to improve long-term outcome in patients undergoing percutaneous coronary intervention," The American Journal of Cardiology, vol. 101, no. 3, pp. 279-285, 2008.

[173] M. Leoncini, A. Toso, M. Maioli, F. Tropeano, and F. Bellandi, "Statin treatment before percutaneous cononary intervention," Journal of Thoracic Disease, vol. 5, no. 3, pp. 335-342, 2013.

[174] B.-C. Zhang, W.-M. Li, and Y.-W. Xu, "High-dose statin pretreatment for the prevention of contrast-induced nephropathy: a meta-analysis," Canadian Journal of Cardiology, vol. 27, no. 6, pp. 851-858, 2011.

[175] M. Andreucci, "Statins in CIN: a problem at least partly solved?" Giornale Italiano di Nefrologia, vol. 30, no. 3, 2013.

[176] M. Sabbatini, A. Pisani, F. Uccello et al., "Atorvastatin improves the course of ischemic acute renal failure in aging rats," Journal of the American Society of Nephrology, vol. 15, no. 4, pp. 901-909, 2004.

[177] K. E. Al-Otaibi, A. M. Al Elaiwi, M. Tariq, and A. K. AlAsmari, "Simvastatin attenuates contrast-induced nephropathy through modulation of oxidative stress, proinflammatory myeloperoxidase, and nitric oxide," Oxidative Medicine and Cellular Longevity, vol. 2012, Article ID 831748, 8 pages, 2012.

[178] C. Quintavalle, D. Fiore, F. de Micco et al., "Impact of a high loading dose of atorvastatin on contrast-induced acute kidney injury," Circulation, vol. 126, no. 25, pp. 3008-3016, 2012.

[179] Y. Han, G. Zhu, L. Han et al., "Short-term rosuvastatin therapy for prevention of contrast-induced acute kidney injury in patients with diabetes and chronic kidney disease," Journal of the American College of Cardiology, vol. 63, no. 1, pp. 62-70, 2014. 
[180] M. Leoncini, A. Toso, M. Maioli, F. Tropeano, S. Villani, and F. Bellandi, "Early high-dose rosuvastatin for contrast-induced nephropathy prevention in acute coronary syndrome: results from the PRATO-ACS study (protective effect of rosuvastatin and antiplatelet therapy on contrast-induced acute kidney injury and myocardial damage in patients with acute coronary syndrome)," Journal of the American College of Cardiology, vol. 63, no. 1, pp. 71-79, 2014.

[181] S. Acikel, H. Muderrisoglu, A. Yildirir et al., "Prevention of contrast-induced impairment of renal function by short-term or long-term statin therapy in patients undergoing elective coronary angiography," Blood Coagulation and Fibrinolysis, vol. 21, no. 8, pp. 750-757, 2010.

[182] G. Patti, E. Ricottini, A. Nusca et al., "Short-term, high-dose atorvastatin pretreatment to prevent contrast-induced nephropathy in patients with acute coronary syndromes undergoing percutaneous coronary intervention (from the ARMYDACIN [atorvastatin for reduction of myocardial damage during angioplasty-contrast-induced nephropathy] trial," The American Journal of Cardiology, vol. 108, no. 1, pp. 1-7, 2011.

[183] G. Marenzi, C. Ferrari, I. Marana et al., "Prevention of contrast nephropathy by furosemide with matched hydration: the MYTHOS (induced diuresis with matched hydration compared to standard hydration for contrast induced nephropathy prevention) trial," JACC: Cardiovascular Interventions, vol. 5, no. 1, pp. 90-97, 2012.

[184] H. H. Neumayer, W. Junge, A. Kufner, and A. Wenning, "Prevention of radiocontrast-media-induced nephrotoxicity by the calcium channel blocker nitrendipine: a prospective randomised clinical trial," Nephrology Dialysis Transplantation, vol. 4, no. 12, pp. 1030-1036, 1989.

[185] D. Russo, A. Testa, L. Della Volpe, and G. Sansone, "Randomised prospective study on renal effects of two different contrast media in humans: protective role of a calcium channel blocker," Nephron, vol. 55, no. 3, pp. 254-257, 1990.

[186] R. Solomon, C. Werner, D. Mann, J. D’Elia, and P. Silva, “Effects of saline, mannitol, and furosemide on acute decreases in renal function induced by radiocontrast agents," The New England Journal of Medicine, vol. 331, no. 21, pp. 1416-1420, 1994.

[187] Z. Khoury, J. R. Schlicht, J. Como et al., "The effect of prophylactic nifedipine on renal function in patients administered contrast media," Pharmacotherapy, vol. 15, no. 1, pp. 59-65, 1995.

[188] B. Spangberg-Viklund, J. Berglund, T. Nikonoff, P. Nyberg, T. Skau, and R. Larsson, "Does prophylactic treatment with felodipine, a calcium antagonist, prevent low-osmolar contrastinduced renal dysfunction in hydrated diabetic and nondiabetic patients with normal or moderately reduced renal function?" Scandinavian Journal of Urology and Nephrology, vol. 30, no. 1, pp. 63-68, 1996.

[189] C. M. Erley, S. H. Duda, S. Schlepckow et al., "Adenosine antagonist theophylline prevents the reduction of glomerular filtration rate after contrast media application," Kidney International, vol. 45, no. 5, pp. 1425-1431, 1994.

[190] R. E. Katholi, G. J. Taylor, W. P. McCann et al., "Nephrotoxicity from contrast media: attenuation with theophylline," Radiology, vol. 195, no. 1, pp. 17-22, 1995.

[191] C. M. Erley, S. H. Duda, D. Rehfuss et al., "Prevention of radiocontrast-media-induced nephropathy in patients with pre-existing renal insufficiency by hydration in combination with the adenosine antagonist theophylline," Nephrology Dialysis Transplantation, vol. 14, no. 5, pp. 1146-1149, 1999.
[192] W. Huber, K. Ilgmann, M. Page et al., "Effect of theophylline on contrast material-induced nephropathy in patients with chronic renal insufficiency: controlled, randomized, doubleblinded study," Radiology, vol. 223, no. 3, pp. 772-779, 2002.

[193] A. S. Abizaid, C. E. Clark, G. S. Mintz et al., "Effects of dopamine and aminophylline on contrast-induced acute renal failure after coronary angioplasty in patients with preexisting renal insufficiency," The American Journal of Cardiology, vol. 83, no. 2, pp. 260-263, 1999.

[194] N. W. Shammas, M. J. Kapalis, M. Harris, D. McKinney, and E. P. Coyne, "Aminophylline does not protect against radiocontrast nephropathy in patients undergoing percutaneous angiographic procedures," Journal of Invasive Cardiology, vol.13, no. 11, pp. 738-740, 2001.

[195] S. Detrenis, M. Meschi, S. Musini, and G. Savazzi, "Lights and shadows on the pathogenesis of contrast-induced nephropathy: State of the art," Nephrology Dialysis Transplantation, vol. 20, no. 8, pp. 1542-1550, 2005.

[196] D. Russo, R. Minutolo, B. Cianciaruso, B. Memoli, G. Conte, and L. de Nicola, "Early effects of contrast media on renal hemodynamics and tubular function in chronic renal failure," Journal of the American Society of Nephrology, vol. 6, no. 5, pp. 1451-1458, 1995.

[197] A. Wang, T. Holcslaw, T. M. Bashore et al., "Exacerbation of radiocontrast nephrotoxicity by endothelin receptor antagonism," Kidney International, vol. 57, no. 4, pp. 1675-1680, 2000.

[198] P. Clauser and C. Harpey, "Antioxidant properties of an antiischaemic agent: trimetazidine," Advances in Experimental Medicine and Biology, vol. 264, pp. 247-250, 1990.

[199] A. Elimadi, A. Settaf, D. Morin et al., "Trimetazidine counteracts the hepatic injury associated with ischemia-reperfusion by preserving mitochondrial function," The Journal of Pharmacology and Experimental Therapeutics, vol. 286, no. 1, pp. 23-28, 1998.

[200] A. Aubert, C. Bernard, P. Clauser, C. Harpey, and H. Vaudry, "Effect of phenazine methosulfate on electrophysiological activity of the semicircular canal: antioxidant properties of trimetazidine," European Journal of Pharmacology, vol. 174, no. 2-3, pp. 215-225, 1989.

[201] A. O. Onbasili, Y. Yeniceriglu, P. Agaoglu et al., "Trimetazidine in the prevention of contrast-induced nephropathy after coronary procedures," Heart, vol. 93, no. 6, pp. 698-702, 2007.

[202] S. S. Hans, B. A. Hans, R. Dhillon, C. Dmuchowski, and J. Glover, "Effect of dopamine on renal function after arteriography in patients with pre-existing renal insufficiency," American Surgeon, vol. 64, no. 5, pp. 432-436, 1998.

[203] A. A. Chamsuddin, K. J. Kowalik, H. Bjarnason et al., "Using a dopamine type $1 \mathrm{~A}$ receptor agonist in high-risk patients to ameliorate contrast-associated nephropathy," American Journal of Roentgenology, vol. 179, no. 3, pp. 591-596, 2002.

[204] A. S. Kini, C. A. Mitre, M. Kamran et al., "Changing trends in incidence and predictors of radiographic contrast nephropathy after percutaneous coronary intervention with use of fenoldopam," The American Journal of Cardiology, vol. 89, no. 8, pp. 999-1002, 2002.

[205] L. S. Weisberg, P. B. Kurnik, and B. R. Kurnik, "Risk of radiocontrast nephropathy in patients with and without diabetes mellitus," Kidney International, vol. 45, pp. 259-265, 1994.

[206] M. Gare, Y. S. Haviv, A. Ben-Yehuda et al., "The renal effect of low-dose dopamine in high-risk patients undergoing coronary angiography," Journal of the American College of Cardiology, vol. 34, no. 6, pp. 1682-1688, 1999. 
[207] G. W. Stone, P. A. McCullough, J. A. Tumlin et al., "Fenoldopam mesylate for the prevention of contrast-induced nephropathy: a randomized controlled trial," The Journal of the American Medical Association, vol. 290, no. 17, pp. 2284-2291, 2003.

[208] A. Y. Kolyada, O. Liangos, N. E. Madias, and B. L. Jaber, "Protective effect of erythropoietin against radiocontrast-induced renal tubular epithelial cell injury," The American Journal of Nephrology, vol. 28, no. 2, pp. 203-209, 2008.

[209] M. Goldfarb, C. Rosenberger, A. Shina, S. Rosen, and S. Heyman, "A role for erythropoietin in the attenuation of radiocontrast-induced acute renal failure in rats," Renal Failure, vol. 28, no. 4, pp. 345-350, 2006.

[210] Y. Yokomaku, T. Sugimoto, S. Kume et al., "Asialoerythropoietin prevents contrast-induced nephropathy," Journal of the American Society of Nephrology, vol. 19, no. 2, pp. 321-328, 2008.

[211] R. Schindler, C. Stahl, S. Venz, K. Ludat, W. Krause, and U. Frei, "Removal of contrast media by different extracorporeal treatments," Nephrology Dialysis Transplantation, vol. 16, no. 7, pp. 1471-1474, 2001.

[212] T. Lehnert, E. Keller, K. Gondolf, T. Schäffner, H. Pavenstädt, and P. Schollmeyer, "Effect of haemodialysis after contrast medium administration in patients with renal insufficiency," Nephrology Dialysis Transplantation, vol. 13, no. 2, pp. 358-362, 1998.

[213] B. Vogt, P. Ferrari, C. Schönholzer et al., "Prophylactic hemodialysis after radiocontrast media in patients with renal insufficiency is potentially harmful," The American Journal of Medicine, vol. 111, no. 9, pp. 692-698, 2001.

[214] V. L. Esnault, "Radiocontrast media-induced nephrotoxicity in patients with renal failure: rationale for a new doubleblind, prospective, randomized trial testing calcium channel antagonists," Nephrology Dialysis Transplantation, vol. 17, no. 8, pp. 1362-1364, 2002.

[215] M. Andreucci, T. Faga, A. Pisani, M. Sabbatini, and A. Michael, "The choice of the iodinated radiographic contrast media to prevent contrast-induced nephropathy," Advances in Nephrology, vol. 2014, Article ID 691623, 11 pages, 2014. 


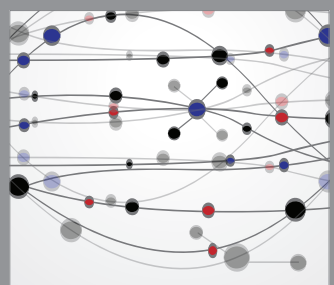

The Scientific World Journal
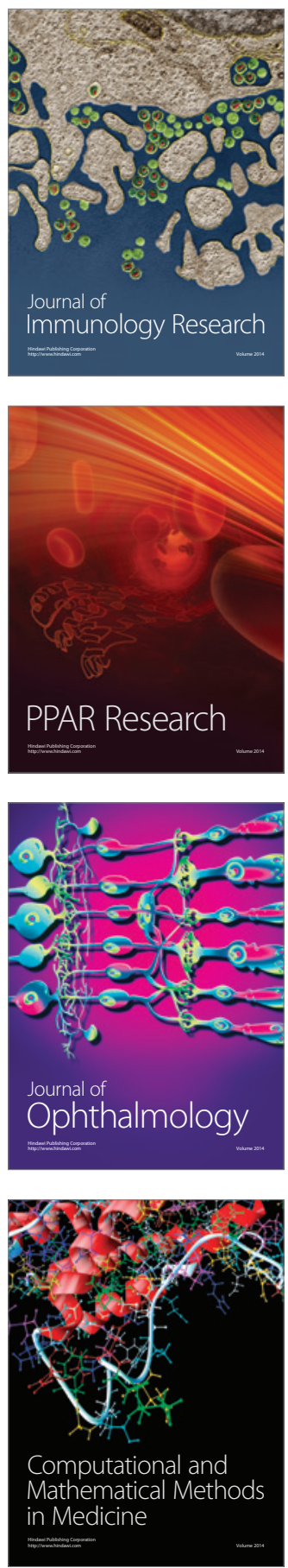

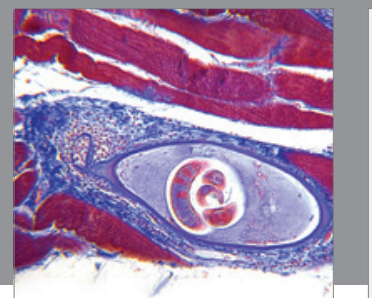

Gastroenterology

Research and Practice
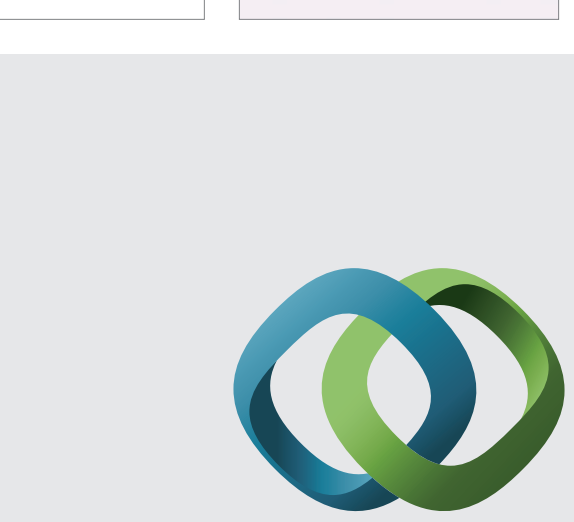

\section{Hindawi}

Submit your manuscripts at

http://www.hindawi.com
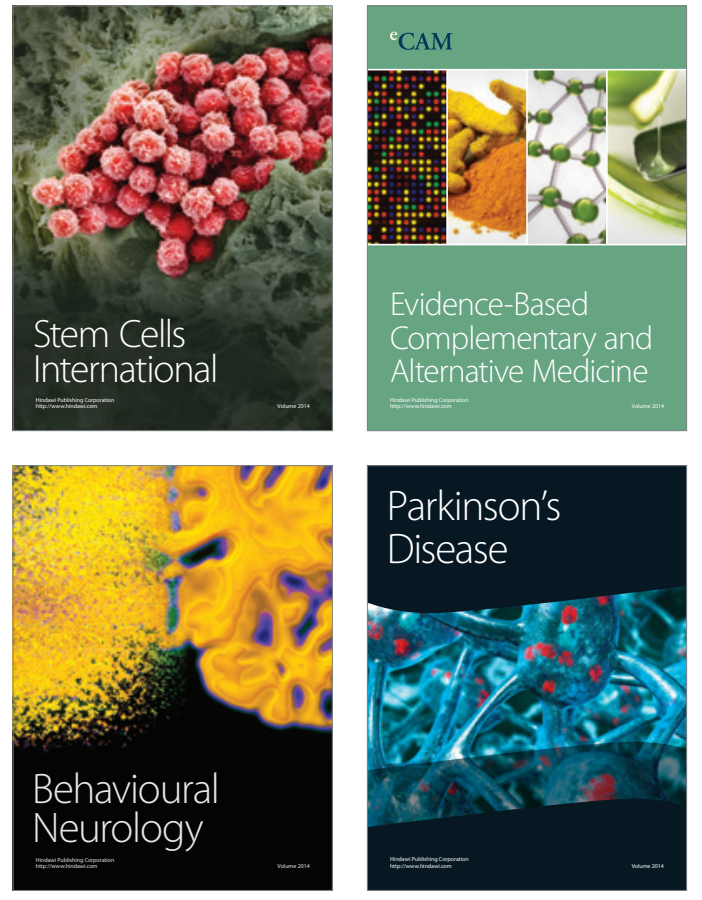
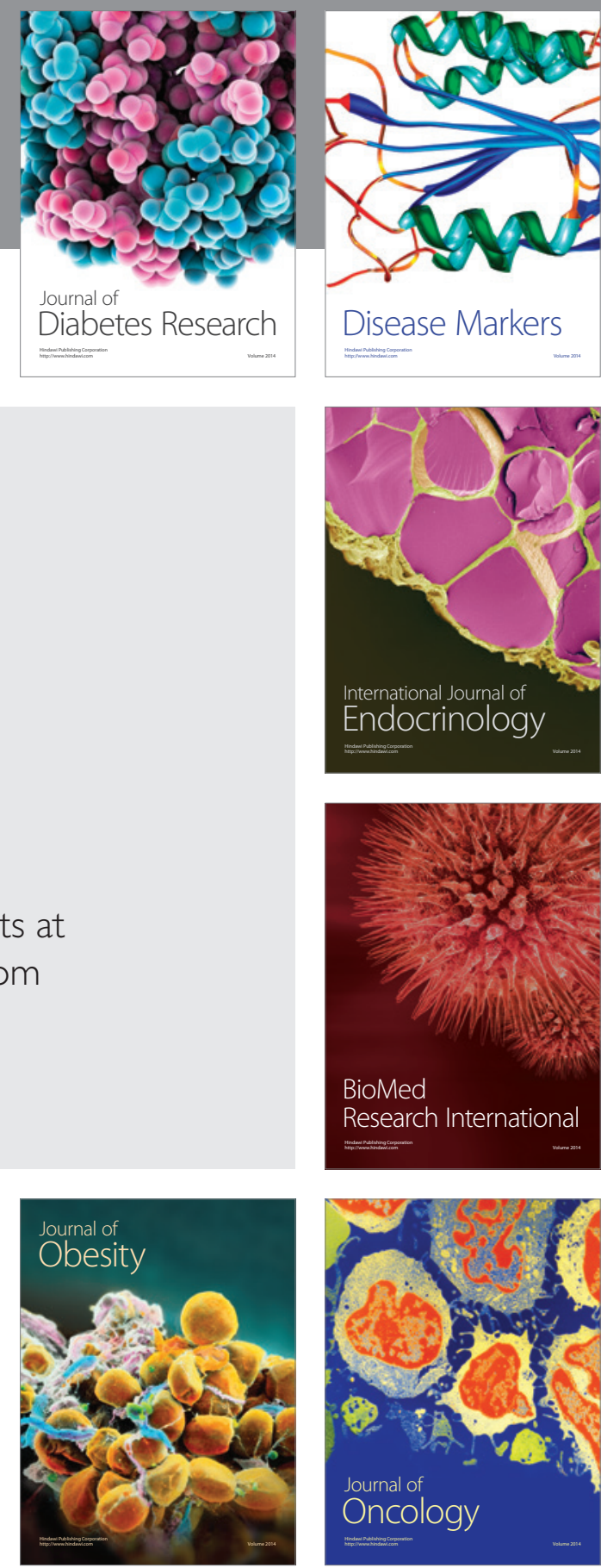

Disease Markers
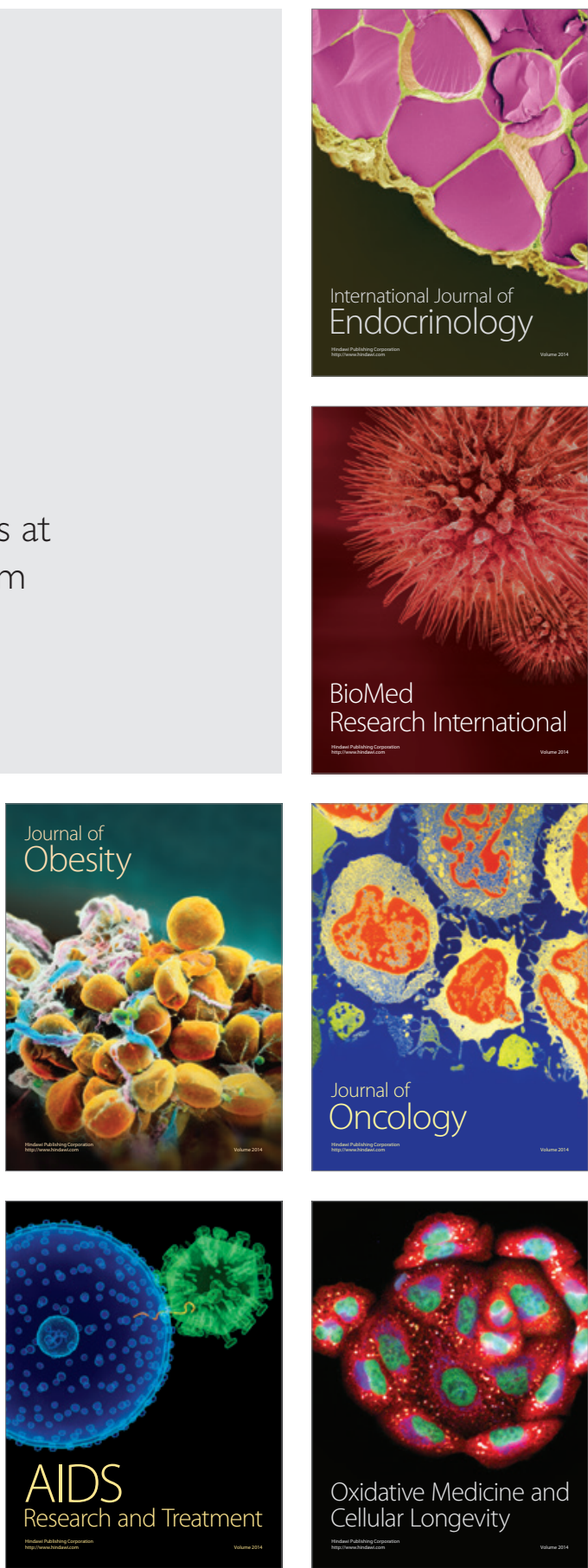